\title{
Phosphodiesterase 8A Regulates CFTR Activity in Airway Epithelial Cells
}

\author{
Mark J. Turnerer, Yukiko Sato ${ }^{a, b}$ David Y. Thomas ${ }^{b, c} \quad$ Kathy Abbott-Banner \\ John W. Hanrahana,b \\ aDepartment of Physiology, McGill University, Montréal, QC, Canada, ${ }^{\mathrm{b} C y s t i c}$ Fibrosis Translational \\ Research Centre, McGill University, Montréal, QC, Canada, 'Department of Biochemistry, McGill \\ University, Montréal, QC, Canada, ${ }^{\mathrm{d}}$ Glaxo-Smith-Kline, GSK House, Brentford, UK
}

\section{Key Words}

CFTR • Cyclic nucleotide phosphodiesterases • Cystic fibrosis • cAMP signalling

\begin{abstract}
Background/Aims: Cystic fibrosis transmembrane conductance regulator (CFTR), the anion channel that is defective in cystic fibrosis (CF), is phosphorylated and activated by CAMPdependent protein kinase (PKA). CAMP levels are downregulated by a large family of phosphodiesterases that have variable expression in different cell types. We have previously observed high levels of PDE8A expression in well-differentiated primary human bronchial epithelial ( $\mathrm{pHBE}$ ) cells and thus aimed to assess whether it played a role in cAMP-dependent regulation of CFTR activity. Methods: We assessed the effect of the selective PDE8 inhibitor PF-04957325 (PF) on intracellular cAMP levels ([cAMP] $]_{i}$ ) in well differentiated pHBE cells from non-CF or CF donors and also in CFBE41o- cells that stably express wild-type CFTR (CFBE41o- WT) using ELISA and FRET-FLIM microscopy. CFTR channel function was also measured using electrophysiological recordings from pHBE and CFBE41o- WT cells mounted in Ussing Chambers. Results: PDE8 inhibition elevated [CAMP $]_{i}$ in well-differentiated pHBE cells and stimulated wild-type CFTR-dependent ion transport under basal conditions or after cells had been pre-stimulated with physiological cAMP-elevating agents. The response to PDE8 inhibition was larger than to PDE3 or PDE5 inhibition but smaller and synergistic with that elicited by PDE4 inhibition. CRISPR Cas9-mediated knockdown of PDE8A enhanced CFTR gene and protein expression yet reduced the effect of PDE8 inhibition. Acute pharmacological inhibition PDE8 increased CFTR activity in CF pHBE cells (F508del/F508del and F508del/R117H5T) treated with clinically-approved CFTR modulators. Conclusion: These results provide the first evidence that PDE8A regulates CFTR and identifies PDE8A as a potential target for adjunct therapies to treat CF.




\section{Cellular Physiology Cell Physiol Biochem 2021;55:784-804

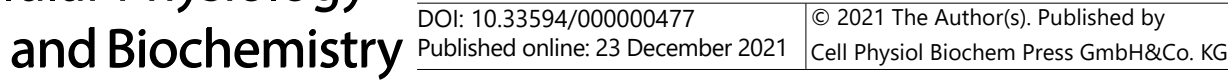 \\ Turner et al.: Phosphodiesterase 8A Regulates CFTR Activity}

\section{Introduction}

The cystic fibrosis transmembrane conductance regulator (CFTR) is a chloride and bicarbonate selective channel expressed at the apical membrane of epithelia in many tissues including the lungs, pancreas, intestine and sweat glands [1,2]. Mutations in cftr cause the disease cystic fibrosis [3-5], which is characterized by reduced anion and fluid secretion and impaired airway immune defense that results in bacterial colonization, chronic inflammation and a gradual decline in pulmonary function [6]. CFTR is tightly regulated by the cAMP/PKA signalling pathway [7], hence components of this pathway have been proposed as therapeutic targets for the treatment of CF. cAMP signalling is terminated when the second messenger is hydrolysed by cyclic nucleotide phosphodiesterases (PDEs).

In humans, PDEs form a superfamily comprising 11 distinct isozymes (PDE1 - 11) and many splice variants, yielding $\sim 100$ enzymes $[8,9]$. PDE4, 7 and 8 are specific for cAMP hydrolysis, PDE5, 6 and 9 hydrolyse cGMP only, and PDE1, 2, 3, 10 and 11 hydrolyse both cyclic nucleotides. Phosphodiesterase inhibitors have been studied for their ability to elevate intracellular cAMP ([cAMP $]_{\mathrm{i}}$ ) and activate CFTR in airway epithelia. PDE3 inhibitors elevate $[\mathrm{CAMP}]_{\mathrm{i}}$ and stimulate CFTR-dependent anion secretion by pig tracheal submucosal glands [10] and in the Calu-3 cell line [10-12], a widely used model for human submucosal gland serous cells [13]. PDE4 inhibitors also activate CFTR in Calu-3 cells $[11,14]$ and in welldifferentiated primary human bronchial surface epithelial cells [15-17].

PDE4 inhibitors potentiate cAMP signaling, increasing CFTR-dependent anion and fluid secretion and production of airway surface liquid $[18,19]$. In addition to regulating wild-type CFTR, they also augment isoproterenol-stimulated secretion by primary human bronchial epithelial cells (pHBE) from patients homozygous for the CFTR mutation F508del after partial rescue of the mutant by corrector drugs [17]. Previously, we showed that the dual PDE3/4 inhibitor ensifentrine (RPL554) enhances forskolin-stimulated CFTR activity in pHBEs with the F508del/R117H-5T genotype [16] as well as rare class III/IV CFTR mutants when they are expressed in FRT cells [20]. There is evidence that the cGMP-specific PDE5 also regulates CFTR in airway epithelia. An analogue of the PDE5 inhibitor sildenafil was identified in a high throughput screen for correctors of F508del CFTR trafficking [21], and Lubamba, et al. [22] found that PDE5 inhibitors stimulate CFTR-dependent $\mathrm{Cl}^{-}$transport across the nasal epithelium in F508del CF mice. Together these results suggest that inhibitors of specific PDE isozymes may have therapeutic value in CF and other diseases in which CFTR function is reduced, such as chronic obstructive pulmonary disease (COPD [23]). For a review of PDE inhibitors in CF see Turner, et al. [24].

In a recent survey of PDE expression in well differentiated pHBE cultures using qPCR we found relatively high levels of PDE8A mRNA [16]. Human PDE8A has 713 amino acids and a catalytic domain with $38.5 \%$ sequence identity to PDE4 [25]. It is most abundant in the testis, ovaries, small intestine and large intestine but has low expression in the lung and other tissues. Compared to PDE4, PDE8A has higher affinity for cAMP when determined in vitro $\left(\mathrm{K}_{\mathrm{m}}=55-155 \mathrm{nM}\right.$ for PDE8A vs $2400 \mathrm{nM}$ for PDE4), lower catalytic turnover $\left(\mathrm{V}_{\max }=150\right.$ pmol min ${ }^{-1} \mu \mathrm{g}^{-1}$ protein for PDE8A vs $2.2 \mathrm{nmol} \mathrm{min}^{-1} \mu \mathrm{g}^{-1}$ protein PDE4) and lower sensitivity to the inhibitor IBMX [25]. It has been postulated to help maintain low basal cAMP levels and is implicated in Raf-1-MEK-ERK signalling [26, 27], cardiac contraction [28], cancer cell migration [29] and testosterone and progesterone steroidogenesis [30-32]. PDE8A was recently shown to downregulate cAMP following activation of $\beta_{2}$-adrenergic receptors in human airway smooth muscle cells [33]. To our knowledge the role of PDE8 in airway epithelium has not been investigated.

Here, we show that PDE8A is functionally expressed in well-differentiated pHBE cells, and also at a lower level in the bronchial epithelial cell line CFBE41o-. Inhibition of PDE8A stimulates wild-type CFTR in pHBE cells and also increases the activity of mutant channels in F508del/F508del and F508del/R117H-5T HBE cells treated with CFTR modulators. The results identify PDE8 as a novel regulator of CFTR and potential therapeutic target for the treatment of CF. 


\section{Cellular Physiology Cell Physiol Biochem 2021;55:784-804 \begin{tabular}{ll|l}
\cline { 2 - 2 } DOl: 10.33594/000000477 & (c) 2021 The Author(s). Published by
\end{tabular} and BiOChemistry Published online: 23 December 2021 Cell Physiol Biochem Press GmbH\&Co. KG \\ Turner et al.: Phosphodiesterase 8A Regulates CFTR Activity}

\section{Materials and Methods}

BHK cells

Baby hamster kidney (BHK) cells were cultured in Dulbecco's MEM/F12 supplemented with $10 \%$ (v/v) FBS, $100 \mathrm{U} \mathrm{ml}^{-1}$ penicillin and $100 \mathrm{\mu g} \mathrm{ml}^{-1}$ streptomycin. For overexpression studies, $5 \times 10^{5}$ cells were seeded onto Corning 6 well plates and incubated at $37^{\circ} \mathrm{C}$ in humidified air containing $5 \% \mathrm{CO}_{2}$ for $48 \mathrm{~h}$. Cells were then transfected with $1 \mu \mathrm{g}$ of human PDE8A in pCMV6-XL5 (Origene) using $3 \mu \mathrm{l} \mathrm{Gene} \mathrm{Juice} \mathrm{(Novagen)}$ in serum-free media. The transfection mix was removed $12 \mathrm{~h}$ later and replaced with complete medium for another $24 \mathrm{~h}$ before cells were studied.

\section{CFBE41o- cells}

We used a CFBE41o- human bronchial epithelial cell line (CFBE41o- WT) kindly provided by Eric Sorscher and Jeong Hong (Emory University School of Medicine) that had been transduced with lentiviral wild-type CFTR as described previously [34]. Cells were cultured in Minimum Essential Media (MEM) supplemented with $10 \%\left(\mathrm{v} / \mathrm{v}\right.$ ) FCS, $100 \mathrm{U} \mathrm{ml}^{-1}$ penicillin, $100 \mathrm{\mu g} \mathrm{ml}^{-1}$ streptomycin and $2 \mathrm{mM} \mathrm{L-glutamine}$ and maintained in $\mathrm{T}_{75}$ flasks (Corning) at $37^{\circ} \mathrm{C}$ in humidified air containing $5 \% \mathrm{CO}_{2}$. For experiments, 80,000 cells were seeded on collagen coated $6.5 \mathrm{~mm}$ dia. Costar ${ }^{\circledR} 0.4 \mu \mathrm{m}$ pore, polyester membrane inserts (Corning) and kept submerged for $24 \mathrm{~h}$, then apical medium was removed and cells were maintained at the air-liquid interface for 1 week prior to study.

\section{Primary human bronchial epithelial ( $p H B E$ ) cell culture}

Non-CF lung specimens were obtained from the International Institute for the Advancement of Medicine (IIAM) and the National Disease Research Institute (NDRI), and cells were isolated by the Primary Airway Cell Biobank (PACB) at McGill University. F508del/R117H-5T cells were from the Tissue Procurement and Cell Culture Core at the UNC CF Center. All procedures were approved by the Institutional Review Board of McGill University (\# A08-M70-14B). The methods for isolation, culture, and differentiation of pHBE cells were adapted from those described previously by Fulcher, et al. [35]. Briefly, cells were isolated by enzyme digestion and cultured in bronchial epithelial growth medium on type I collagen-coated plastic flasks (PureCol; Advanced BioMatrix), then trypsinized, counted, and cryopreserved. For experiments, cells were seeded on collagen coated $6.5 \mathrm{~mm}$ dia. Costar ${ }^{\circledR} 0.4 \mu \mathrm{m}$ pore, polyester membrane inserts (Corning), and kept submerged for 4 days, then the apical medium was removed and the cells were allowed to differentiate at an air-liquid interface (ALI) for $\geq 21$ days before study. The growth medium was complemented with penicillin, streptomycin and gentamycin antibiotics according to recent patient microbiology reports. In total, pHBE cells isolated from 11 different donors were studied of which 8 were male and the age range of donors was 31-69.

\section{CRISPR-Cas9-mediated gene editing}

CFBE41o- WT cells were nucleofected with CRISPR sgRNA (pCLIP-Dual-SFFV-ZsGreen) and pCLIPCas9-hCMV-Blast from the transEDIT-dual library (TransOMIC Technologies) at the McGill Platform for Cellular Perturbation of the Goodman Cancer Research Centre and Department of Biochemistry at McGill University. After transfection, cells were cultured in CFBE41o- culture medium containing puromycin $\left(4 \mu \mathrm{g} \mathrm{ml}^{-1}\right)$ and blasticidin $\left(10 \mu \mathrm{g} \mathrm{ml}^{-1}\right)$ for cell selection. Expression of Cas9 was tested by qPCR and expression of sgRNA was assessed by confocal microscopy (data not shown). After a stable population of cells was acquired, they were sorted into single clones by fluorescence-activated cell sorting (FACS). Single cell clones were cultured and the knockdown of PDE8A was assessed by qPCR.

\section{RNA extraction and quantitative real-time PCR}

Total cellular RNA was extracted and purified using the Illustra ${ }^{\mathrm{TM}}$ RNAspin Mini RNA Isolation Kit (GE Healthcare) according to manufacturer's instructions. For reverse transcription, $300 \mathrm{ng}$ RNA was incubated with 5x All-In-One RT Mastermix (ABM) in a reaction volume of $20 \mu \mathrm{l}$ for $10 \mathrm{~min}$ at $25^{\circ} \mathrm{C}, 15 \mathrm{~min}$ at $42^{\circ} \mathrm{C}$ and $5 \mathrm{~min}$ at $85^{\circ} \mathrm{C} .0 .5 \mu \mathrm{l} \mathrm{cDNA}, 10 \mu \mathrm{l}$ of TaqMan ${ }^{\circledR}$ Fast Advanced Mastermix, $1 \mu \mathrm{l}$ of TaqMan $\AA$ Gene Expression Assay in a reaction volume of $20 \mu \mathrm{l}$ was added to the wells of a MicroAmp® EnduraPlate ${ }^{\mathrm{TM}}$ Optical 96-Well Fast Reaction Plate. The qPCR was carried out using a QuantStudio ${ }^{T M} 7$ Flex Real-Time PCR system and the 


\section{Cellular Physiology Cell Physiol Biochem 2021;55:784-804 \\ \begin{tabular}{ll|l} 
DOl: 10.33594/000000477 & O 2021 The Author(s). Published by \\
and Biochemistry & Published online:23 December 2021 & Cell Physiol Biochem Press GmbH\&Co. KG \\
\cline { 2 - 3 }
\end{tabular} \\ Turner et al.: Phosphodiesterase 8A Regulates CFTR Activity}

following protocol: $20 \mathrm{~s}$ at $95^{\circ} \mathrm{C}$ and 40 cycles at $95^{\circ} \mathrm{C}(1 \mathrm{~s})$ and $60^{\circ} \mathrm{C}(20 \mathrm{~s}) \cdot \Delta \Delta \mathrm{C}_{\mathrm{T}}$ analysis was performed using the manufacturer's software package. The efficiency of each TaqMan® Gene Expression Assay used in this study was $95-105 \%$.

\section{Immunoblotting}

pHBE cells, CFBE41o- WT cells or BHK cells were lysed in RIPA buffer containing $150 \mathrm{mM} \mathrm{NaCl}, 20 \mathrm{mM}$ Tris, $0.1 \%$ SDS (w/v), $1 \%$ Triton X-100 (w/v), $0.08 \%$ sodium deoxycholate $(\mathrm{pH} 8.0)$ and a protease inhibitor cocktail tablet (Roche). For experiments that involve detection of phosphorylated proteins, RIPA buffer was supplemented with a phosphatase inhibitor cocktail tablet (Roche). $40 \mu \mathrm{g}$ protein was resolved by SDSPAGE before transferring to a nitrocellulose membrane. Rabbit anti-PDE8A (1:5000; Abcam; ab109597), rabbit anti Phospho-PKA substrate (1:1000; Cell Signalling Technology) rabbit anti-actin (1:2500; Abcam; ab8227) or mouse anti-tubulin (1:2000; Sigma) primary antibodies were added to the blot overnight at $4^{\circ} \mathrm{C}$. The membrane was washed with Tris Buffered Saline (TBS) $+0.1 \%$ Tween-20 (TBS-T) and secondary antibodies conjugated with HRP were added at 1:10,000 dilution in TBS-T for $1 \mathrm{~h}$. To detect HRP activity, equal volumes of Amersham ${ }^{\mathrm{TM}} \mathrm{ECL}^{\mathrm{TM}}$ Western Blotting Reagents (GE Lifesciences) were added for $10 \mathrm{~min}$ before exposing the blot to Kodak Scientific Imaging film for $30 \mathrm{~s}$ and processing (Mini-Med/90, AFP Imaging) or developing the blot using a ChemiDoc MP Imaging System (Bio-Rad).

\section{Intracellular cAMP measurements using ELISA}

$24 \mathrm{~h}$ prior to study, pHBE or CFBE41o- WT cells were washed $3 \mathrm{x}$ with PBS and cultured in serum- and antibiotic-free medium. Cells were then incubated in high $\mathrm{Cl}$ saline solution, stimulated with pharmacological agonists, and incubated at $37^{\circ} \mathrm{C}$ in humidified air containing $5 \% \mathrm{CO}_{2}$ for 15 min prior to lysis with $0.1 \mathrm{M}$ $\mathrm{HCl}$. cAMP levels were determined using an intracellular cAMP ELISA kit (Enzo Life Sciences) following manufacturer's instructions.

\section{Intracellular cAMP measurements using FLIM-FRET microscopy}

The Epac-S ${ }^{\mathrm{H} 187}$ FRET construct was a gift from Dr Kees Jalink (Netherlands Cancer Institute). It encodes a high affinity Epac1 sensor flanked by a mTurquoise2 donor and tandem Venus acceptor ${ }^{\mathrm{cpp} 173}$ Venus ${ }^{\text {cpp } 173}$ Venus [36]. mTurquoise2-N1 was from Michael Davidson and Dorus Gadella (Addgene plasmid \# 54843; http:// n2t.net/addgene:54843 [37]). To target Epac- $\mathrm{S}^{\mathrm{H} 87}$ to the cell membrane, the first 13 amino acids of Lyn tyrosine protein kinase were added to the $\mathrm{N}$ terminus by Genscript Biotech (Piscataway, NJ). Elevated cAMP concentration induces a conformational change in Epac1 and reduces FRET between the mTurquoise 2 and Venus regions of the fusion protein, increasing the lifetime of mTurquoise2. One million CFBE41o- WT cells were transfected with $3 \mu \mathrm{g}$ of the FRET constructs using an Amaxa $^{\mathrm{TM}}$ 4D-Nucleofector ${ }^{\mathrm{TM}}$ System with the Amaxa $^{\mathrm{TM}}$ P3 Primary Cell 4D-Nucleofector ${ }^{\mathrm{TM}} \mathrm{X}$ Kit (program DC100) and seeded onto fibronectin-coated, $35 \mathrm{~mm}$ FluoroDish ${ }^{\mathrm{TM}}$ (World Precision Instruments, Sarasota FL) cell culture dishes. Experiments were performed 24-48 h post transfection. Fluorescence lifetime images were acquired using a Zeiss LSM-710FLIM (PicoQuant, Berlin, Germany) microscope at x20 magnification and cells were excited using a 440 $\mathrm{nm}$ laser in pulse mode at $20 \mathrm{MHz}$. Photons were collected for $120 \mathrm{~s}$ using a time-correlated single photon counting (TCSPC) device coupled to the microscope and CFP bandpass emission filter (480 $\pm 20 \mathrm{~nm}$ ). Lifetime measurements of mTurquoise 2 were calculated by performing a double exponential, reconvolution fit of the TCSPC histogram, which generated the average lifetime using the following equation:

$$
\text { Lifetime }=\frac{\sum \text { Amplitude } \cdot \tau^{2}}{\sum \text { Amplitude } \cdot \tau}
$$

\section{Short circuit current measurements}

One day prior to study, pHBE or CFBE41o- WT cells were washed $3 \mathrm{x}$ with PBS and cultured in serumand antibiotic-free medium. Cells were mounted in modified Ussing chambers (Physiologic Instruments, San Diego, CA) containing $5 \mathrm{ml}$ saline, which was continuously gassed with $5 \% \mathrm{CO}_{2} / 95 \% \mathrm{O}_{2}$. Monolayers were clamped at $0 \mathrm{mV}$ using a Multichannel Voltage-Current Clamp (Physiologic Instruments) and currents recorded using a Powerlab 8SP (AD Instruments, Dunedin, NZ) and analyzed using LabChart 7.0 software. Transepithelial resistance $\left(R_{\text {te }}\right)$ was monitored by applying a $1 \mathrm{mV}$ pulse (duration: $2 \mathrm{~s}$ ) every $30 \mathrm{~s}$ and resistance calculated using Ohm's Law. All drugs were added apically unless otherwise stated. 


\section{Cellular Physiology Cell Physiol Biochem 2021;55:784-804

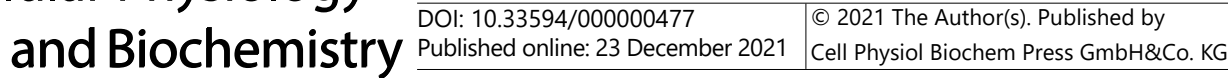 \\ Turner et al.: Phosphodiesterase 8A Regulates CFTR Activity}

Solutions and reagents

$\mathrm{CFTR}_{\mathrm{inh}}-172$ was kindly provided by R. Bridges, Rosalind Franklin Univ. of Medicine and Science, North Chicago IL, and Cystic Fibrosis Foundation Therapeutics. Ensifentrine was obtained from Verona Pharma (London, UK) and PF-04957325 was obtained from the Compound Transfer Program (Pfizer) and MedChem Express. Reagents for cell culture were purchased from Wisent unless otherwise stated, and all other reagents were purchased from Sigma-Aldrich. For I measurements, in non-permeabilized conditions, the basolateral saline solution contained (mM): $115 \mathrm{NaCl}, 25 \mathrm{NaHCO}_{3}, 1.2 \mathrm{MgCl}_{2}, 1.2 \mathrm{CaCl}_{2}, 2.4 \mathrm{KH}_{2} \mathrm{PO}_{4}, 1.24$ $\mathrm{K}_{2} \mathrm{HPO}_{4}$, and $10 \mathrm{D}$-Glucose and the apical saline solution contained (mM): $1.2 \mathrm{NaCl}, 115 \mathrm{Na}$-gluconate, 25 $\mathrm{NaHCO}_{3}, 1.2 \mathrm{MgCl}_{2}, 4 \mathrm{CaCl}_{2}, 2.4 \mathrm{KH}_{2} \mathrm{PO}_{4}, 1.24 \mathrm{~K}_{2} \mathrm{HPO}_{4}$, and 10 D-glucose; In permeabilized conditions, the basolateral saline solution contained (mM): $1.2 \mathrm{NaCl}, 115 \mathrm{Na}$-gluconate, $25 \mathrm{NaHCO}_{3}, 1.2 \mathrm{MgCl}_{2}, 4 \mathrm{CaCl}_{2}$, $2.4 \mathrm{KH}_{2} \mathrm{PO}_{4}, 1.24 \mathrm{~K}_{2} \mathrm{HPO}_{4}$, and $10 \mathrm{D}$-glucose and the apical saline solution contained (in mM) $115 \mathrm{NaCl}, 25$ $\mathrm{NaHCO}_{3}, 1.2 \mathrm{MgCl}_{2}, 1.2 \mathrm{CaCl}_{2}, 2.4 \mathrm{KH}_{2} \mathrm{PO}_{4}, 1.24 \mathrm{~K}_{2} \mathrm{HPO}_{4}$, and $10 \mathrm{D}-\mathrm{Mannitol}$. All solutions were adjusted to $\mathrm{pH}$ 7.4 when gassed with $5 \% \mathrm{CO}_{2} / 95 \% \mathrm{O}_{2}$.

\section{Statistical analysis}

Data are displayed as mean \pm S.D. unless otherwise stated. Sample sizes are displayed as $n$, the number of inserts and $\mathrm{N}$, the number of donors or independent cell cultures where applicable. Statistical analysis was performed using GraphPad Prism 5 software. Student's t-test, one-way ANOVA (with Tukey's multiple comparison post-test) or two-way ANOVA (with Bonferroni post-test) were carried out with $\mathrm{p}<0.05$ considered significant. The coefficiency of drug interaction (CDI) was calculated as $A B /(A \times B)$, where $A B$ represents the effect of both drugs together and $A$ and $B$ represent the effects of drug $A$ and drug $B$ when tested individually. A CDI of $>1$ indicates synergistic stimulation by drugs in combination [38].

\section{Results}

PDE8A is expressed in well-differentiated human airway epithelia

We began by assessing PDE8A expression using pHBE cells and comparing its level to that of 6 other PDEs for which there is evidence in airway epithelial cells [39-41]. High PDE8A mRNA expression was detected in pHBE cell lysates that was comparable to that for PDE4D, widely considered to be the main PDE regulating CFTR in HBE cells, after normalization to GAPDH (Fig. 1A). These results are consistent with our previous study of pHBE cell lysates from three different cell donors [16]. We also observed PDE8A mRNA in CFBE41o- cells that stably express wild-type CFTR (CFBE41o- WT), although levels were lower than in pHBE cells (Fig. 1B). We assessed PDE8A protein expression by immunoblotting and observed a band with the expected molecular mass in both pHBE and CFBE41o- WT cells, again with lower expression in the latter. No PDE8A was observed in control BHK cell lysates, however a strong band appeared when PDE8A was transiently overexpressed (Fig. 1C). These results indicate that PDE8A mRNA and protein are highly expressed in well-differentiated human airway epithelial cells and at a low level in the CFBE410- cell line.

Inhibiting PDE8 in pHBE cells increases basal and forskolin-stimulated [cAMP] $]_{i}$

PDE8 is a high affinity, cAMP-specific PDE [25], therefore its inhibition is predicted to elevate $[\mathrm{cAMP}]_{\mathrm{i}}$ above basal levels. We used the PDE8 selective inhibitor PF-04957325 (PF) that has the following $\mathrm{IC}_{50}$ 's in vitro: PDE8A $=0.0007 \mu \mathrm{M}, \mathrm{PDE} 8 \mathrm{~B}<0.0003 \mu \mathrm{M}$, and $>1.5 \mu \mathrm{M}$ for all other PDEs tested [26]. Well-differentiated, non-CF pHBEs were treated for $15 \mathrm{~min}$. This increased [cAMP] $1.36 \pm 0.11$-fold compared to cells treated with vehicle $(p<0.01$; $\mathrm{n}=19, \mathrm{~N}=4$; Fig. 2) indicating that basal cAMP levels are regulated by PDE8. PF also enhanced forskolin-stimulated cAMP levels from $3.09 \pm 0.27$ to $4.97 \pm 0.55(\mathrm{p}<0.01 ; \mathrm{n}=16, \mathrm{~N}=4 ;$ Fig. 2). The dual PDE3/4 inhibitor ensifentrine (Verona Pharma) and isoproterenol caused larger increases in $[\mathrm{CAMP}]_{\mathrm{i}}$ that were not further elevated by PF (Fig. 2). These results suggest that PDE8 regulates cAMP levels in pHBE cells. 


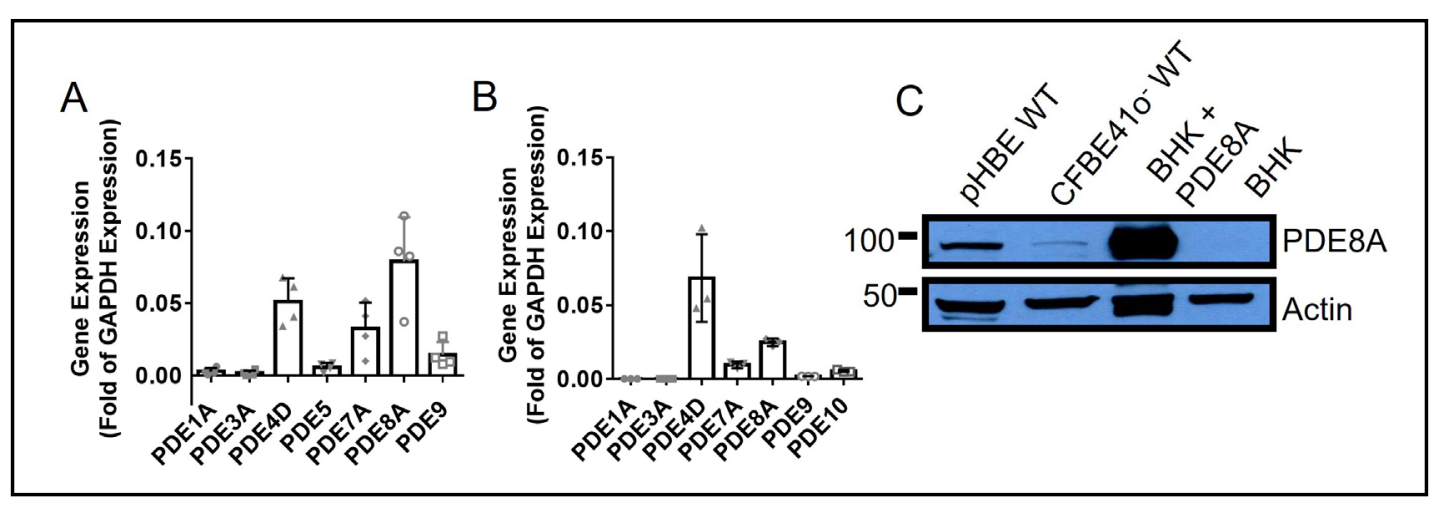

Fig. 1. PDE8A mRNA and protein is expressed in human airway epithelial cells. (A) and (B) mRNA expression for different PDE isoforms in polarized, well-differentiated non-CF pHBEs or CFBE41o- WT cells respectively. Data represents the expression of each PDE isoform after normalization to GAPDH in the same sample. Data expressed as mean \pm S.D. of $n=5$ different patients ( $p H B E$ ) and $n=3$ independent cultures (CFBE41o- WT). (C) immunoblot of non-CF, primary HBE and CFBE41o- WT cell lysates, and BHK cells transfected or not with $3 \mu \mathrm{g}$ PDE8A cDNA. Immunoblots were performed on protein lysates generated from 3 independent cell cultures.

Fig. 2. Inhibiting PDE8 increases $[\mathrm{CAMP}]_{\mathrm{i}}$ in non-CF, primary HBE cells. Polarized, well differentiated non-CF pHBE cells were treated for 15 min with DMSO, PF (PF-04957325, $500 \mathrm{nM}$ ), forskolin (Fsk, $2 \mu \mathrm{M})$, Fsk + PF, ensifentrine (Ens; $10 \mu \mathrm{M})$, Ens $+\mathrm{PF}$, isoproterenol (Iso; $1 \mu \mathrm{M}$ ) or Iso $+\mathrm{PF}$ then lysed and analysed for $\left.{ }_{\mathrm{CAMP}}\right]_{\mathrm{i}}$ using ELISA. [cAMP $]_{\mathrm{i}}$ was normalized for intracellular protein concentration (pmol cAMP per mg of cellular protein) and levels under different conditions are expressed relative to those in vehicle (DMSO)-treated cells. Mean \pm S.D., $n=9-19$; $\mathrm{N}=3-4{ }^{* *}=$ significant increase vs. DMSO treated cells $(\mathrm{p}<0.01$; $* * * * \mathrm{p}<0.0001) . \dagger=$ significant effect of PF in FSK-stimulated cells

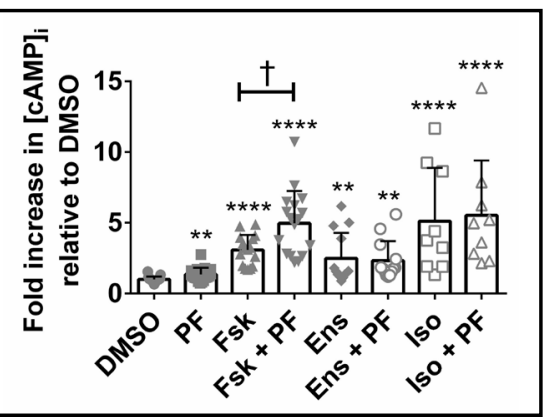
$(\mathrm{p}<0.01)$.

Inhibiting PDE8 stimulates CFTR-dependent secretion by $p H B E$ cells

Having established that PDE8 inhibition modulates [cAMP] $]_{i}$ in well-differentiated, nonCF pHBE cells, we next measured $\mathrm{I}_{\mathrm{sc}}$ responses to determine if PDE8 inhibition increases CFTR activity. Under basal conditions, PF increased the $\mathrm{I}_{\mathrm{sc}}$ by $1.67 \pm 1.50 \mu \mathrm{A} \mathrm{cm}{ }^{-2}(\mathrm{p}<0.0001$ vs DMSO; $\mathrm{n}=31 ; \mathrm{N}=7$ ) and this response was abolished by the CFTR channel inhibitor CFTR $_{\text {inh }}-172$ (Fig. 3A). We then compared the $\mathrm{I}_{\mathrm{sc}}$ response to PDE8 inhibition after cells had been pre-treated with forskolin, isoproterenol or adenosine (Fig. 3B-3D). These cAMP elevating agents caused $\mathrm{I}_{\mathrm{sc}}$ increases in the rank order forskolin $>$ isoproterenol > adenosine (Fig. 3E). Adding PF after these agents further enhanced $\mathrm{I}_{\mathrm{sc}}$ by $2.68 \pm 0.43 \mu \mathrm{A} \mathrm{cm}^{-2}, 5.29 \pm 0.65$ $\mu \mathrm{A} \mathrm{cm}^{-2}$ and $2.61 \pm 0.34 \mu \mathrm{A} \mathrm{cm}^{-2}$, respectively $(\mathrm{n}=11-18, \mathrm{~N}=3-4 ;$ Fig. 3F). The increase with PF was larger during stimulation by isoproterenol than in unstimulated cells, or in cells exposed to forskolin or adenosine ( $\mathrm{p}<0.01$; Fig. $3 \mathrm{~F}$ ). These results demonstrate that inhibiting PDE8 stimulates CFTR under both basal and stimulated conditions and is most effective for the $\beta_{2}$ adrenergic receptor agonist isoproterenol.

We compared responses to PF to other PDE inhibitors in human airway epithelium after pre-stimulation by forskolin or isoproterenol. Neither milrinone (PDE3 inhibitor) nor sildenafil (PDE5 inhibitor) further increased stimulation by forskolin or isoproterenol (Fig. 4), whereas roflumilast (PDE4 inhibitor) increased forskolin and isoproterenol-stimulated $\mathrm{I}_{\mathrm{sc}}$ by $9.72 \pm 1.09 \mu \mathrm{A} \mathrm{cm}^{-2}(\mathrm{n}=9, \mathrm{~N}=3)$ and $15.85 \pm 2.90 \mu \mathrm{A} \mathrm{cm}^{-2}(\mathrm{n}=9, \mathrm{~N}=3)$, respectively (Fig. 4C). 
Roflumilast was more effective than PF in stimulating CFTR-dependent $\mathrm{I}_{\mathrm{sc}^{\prime}}$ confirming PDE4 as the predominant PDE that regulates CFTR in well differentiated pHBE cells. However, the data indicate that PDE8 also has an important functional role.

Fig. 3. Inhibiting PDE8 stimulates CFTR-dependent $\mathrm{I}_{\mathrm{sc}}$ in non-CF, primary HBE cells. Polarized, well differentiated primary HBE cells were mounted in Ussing chambers and $\mathrm{I}_{\mathrm{sc}}$ was measured. In each experiment, cells were treated with apical amiloride (Amil; $100 \mu \mathrm{M}$ ) to block ENaC-dependent currents and CFTR $_{\text {inh }}-172$ (172; $10 \mu \mathrm{M}$ ) was used to test if $\mathrm{I}_{\mathrm{sc}}$ was CFTR-dependent. ATP $(100 \mu \mathrm{M})$ was added at the end
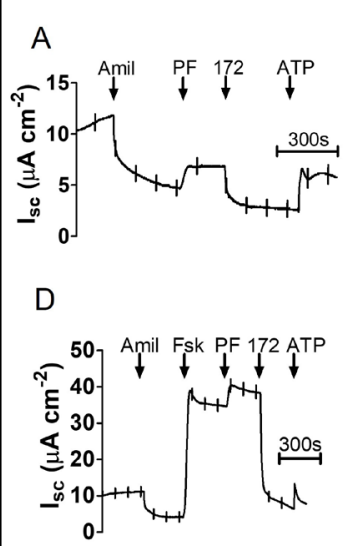
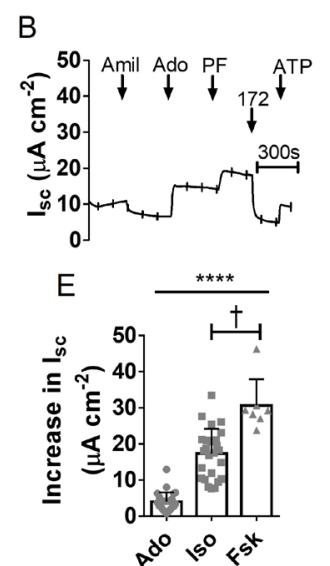

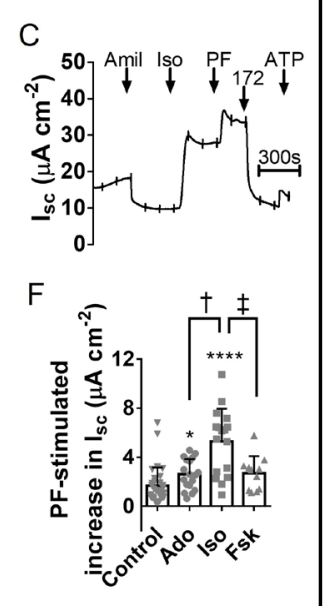
of each experiment to confirm that the cells were functional.

(A) (B) (C) and (D) show typical traces demonstrating effect of PF in basal, adenosine (Ado; $10 \mu \mathrm{M}$ ), isoproterenol (Iso; $1 \mu \mathrm{M}$ ) and forskolin (Fsk; $2 \mu \mathrm{M}$ )-stimulated cells respectively. (E) summary of the increases in $\mathrm{I}_{\mathrm{sc}}$ produced by each cAMP agonist **** significant between Ado vs Iso and Ado vs Fsk $(\mathrm{p}<0.0001) \dagger$ significant between Fsk vs Iso $(\mathrm{p}<0.01)$ Data represents mean \pm S.D.; $\mathrm{n}=7-26$; $\mathrm{N}=3$. (F) summary of the increase in $\mathrm{I}_{\mathrm{sc}}$ produced by $\mathrm{PF}$ after pre-stimulation. Mean \pm S.D..; $\mathrm{n}=11-24 ; \mathrm{N}=4-5$. * Significant vs control (i.e. no pre-stimulation) $\left(\mathrm{p}<0.05 ;{ }^{* * * *} \mathrm{p}<0.0001\right)$. † Significant vs Ado $(\mathrm{p}<0.001)$; $\ddagger$ significant vs Fsk $(\mathrm{p}<0.01)$.

Fig. 4. PDE4 is the predominant PDE regulating CFTR in non-CF pHBE cells Polarized, well differentiated primary HBE cells were mounted in Ussing chambers and $\mathrm{I}_{\mathrm{sc}}$ was measured. In each experiment, cells were first treated with apical amiloride (Amil; $100 \mu \mathrm{M}$ ) to block ENaC-dependent currents. CFTR $_{\text {inh }}-172(172 ; 10 \mu \mathrm{M})$ was added to establish that changes in $\mathrm{I}_{\mathrm{sc}}$ were CFTR-dependent. ATP $(100 \mu \mathrm{M})$ was added at the end to confirm that the cells were functional. (A) and (B) show representative experiments in which cells were pre-stimulated with forskolin (Fsk; $2 \mu \mathrm{M}$ ) or isoproterenol (Iso; $1 \mu \mathrm{M})$ respectively followed by roflumilast $(1 \mu \mathrm{M})$ or PF (500 nM). (C) summary of $I_{\text {sc }}$ responses to the PDE inhibitors milrinone (Mil; $10 \mu \mathrm{M}$ ), roflumilast (Rofl; $1 \mu \mathrm{M}$ ), sildenafil (Sil; $10 \mu \mathrm{M}$ ) and PF (500 $n M)$. Mean \pm S.D., $n=3-10 ; \mathrm{N}=3$. * Significant effect of PDE vs DMSO pre-treatment $\left(\mathrm{p}<0.05 ;{ }^{* *} \mathrm{p}<0.01 ;{ }^{* * *} \mathrm{p}<0.001\right)$. $†$ Significant vs Rofl in forskolin-stimulated cells $(\mathrm{p}<0.001) \neq$ significant vs Rofl in isoproterenol-stimulated cells $(\mathrm{p}<0.01)$.

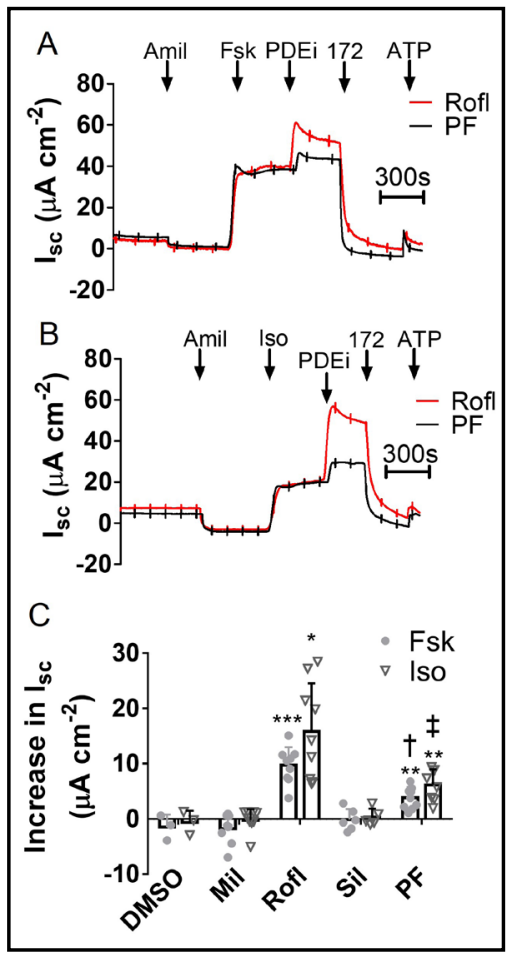




\section{Cellular Physiology Cell Physiol Biochem 2021;55:784-804 \\ \begin{tabular}{ll|l} 
and Biochemistry & $\begin{array}{l}\text { DOl: 10.33594/000000477 } \\
\text { Published online:23 December 2021 }\end{array}$ & $\begin{array}{l}\text { C } 2021 \text { The Author(s). Published by } \\
\text { Cell Physiol Biochem Press GmbH\&Co. KG }\end{array}$
\end{tabular} \\ Turner et al.: Phosphodiesterase 8A Regulates CFTR Activity}

Inhibiting PDE8 enhances the CFTR response to PDE4 inhibitors and vice versa

We next compared the effects of PDE inhibitors individually and in combination under basal conditions. Without prestimulation, neither milrinone nor sildenafil stimulated $\mathrm{I}_{\mathrm{sc}}$ across well-differentiated pHBE cells whereas PF, roflumilast and ensifentrine all generated small, but significant increases in $\mathrm{I}_{\mathrm{sc}}$ (Fig. 5A and 5B). This implies that PDE4 and PDE8 inhibitors may cause similar elevation of basal cAMP levels in pHBE cells (Fig. 5C). Pretreating cells with PF enhanced roflumilast and ensifentrine stimulation of $\mathrm{I}_{\mathrm{sc}}$ by $2.25 \pm 1.13$ fold $(p<0.05 ; n=5, N=2$; Fig. 5C) and $3.83 \pm 0.83$ fold, respectively ( $<<0.05 ; n=6-9, N=2$, Fig. 5C) but did not affect milrinone- and sildenafil-stimulated currents. Conversely, pretreating cells with roflumilast or ensifentrine increased the PF response by $4.43 \pm 1.41$ fold $(\mathrm{p}<0.05$; $\mathrm{n}=5, \mathrm{~N}=2$; Fig. 5D) and $4.50 \pm 1.18$ fold ( $<0.01 ; \mathrm{n}=6, \mathrm{~N}=2$; Fig. 5D), respectively, but did not alter responses to milrinone or sildenafil. The calculated coefficiency of drug interaction (CDI) was greater than 1, indicating that PDE4 and PDE8 inhibitor effects on CFTR activity are synergistic when used in combination.

PDE8 inhibition does not cause a measurable increase in global [cAMP] in CFBE41o-WT cells

Having shown that PDE8 regulates CFTR in pHBE cells, we next used polarized CFBE41o- WT cells as a model to further explore PDE8-dependent regulation of CFTR given that they express PDE8A mRNA and protein, albeit at lower levels than pHBE cells (see Fig. 1). Measurements of [cAMP] $]_{i}$ using ELISA showed that PF did not elevate total [cAMP $]_{i}$ above that of DMSO-treated cells (fold increase $=1.45 \pm 0.28 ; p>0.05$ vs DMSO; $n=20, N=5$; Fig. $6 \mathrm{~A}$ ). Forskolin and ensifentrine both increased [cAMP $]_{\mathrm{i}}$ compared to DMSO-treated cells (fold increase $=134.9 \pm 25.39$ and $11.67 \pm 2.97$ respectively; $\mathrm{p}<0.001$ vs. DMSO; $\mathrm{n}=7-12 ; \mathrm{N}=3$ ), however there was no further increase when either treatment was combined with PF (Fig. 6A). We also measured [cAMP] in CFBE410- WT cells using Fluorescence lifetime imaging microscopy (FLIM) with the high affinity Exchange protein activated by cAMP (EPAC)-based Förster resonance energy transfer (FRET) sensor EPAC-S ${ }^{\mathrm{H} 187}$, which consists of EPAC flanked

Fig. 5. PDE4 inhibitors enhance CFTR stimulation by PDE8 inhibition and vice versa. Polarized, well differentiated primary HBE cells were mounted in Ussing chambers and $\mathrm{I}_{\mathrm{sc}}$ was measured. In each experiment, cells were first treated with apical amiloride (Amil; $100 \mu \mathrm{M}$ ) to block ENaC-dependent currents. CFTR $_{\text {inh }}-172(172 ; 10 \mu \mathrm{M})$ was added to establish that changes in $\mathrm{I}_{\mathrm{sc}}$ were CFTR-dependent. ATP $(100 \mu \mathrm{M})$ was added at the end to confirm that the cells were functional. (A) shows a representative experiment in which the effect of
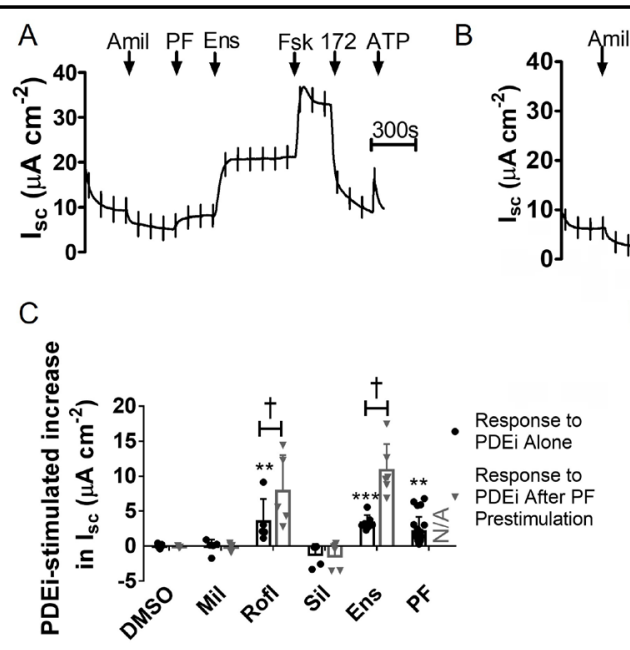
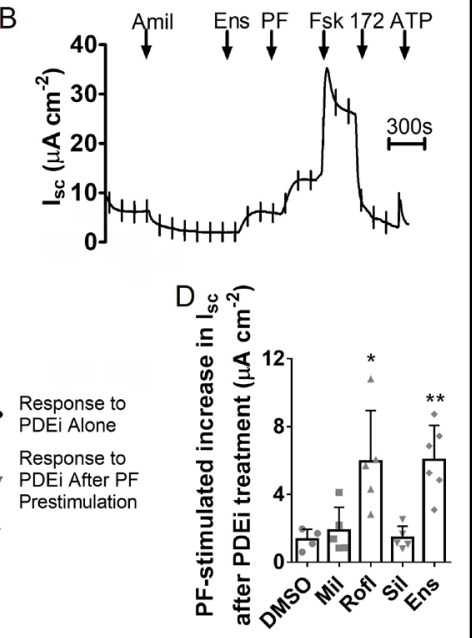

PDE4 inhibition was assessed after

PF pre-stimulation and (B) shows a representative experiment in which the effect of PF was assessed after PDE4 inhibition. (C) summary of the effect of the PDE inhibitors milrinone (Mil; $10 \mu \mathrm{M}$ ), roflumilast (Rofl; $1 \mu \mathrm{M})$, sildenafil (Sil; $10 \mu \mathrm{M})$ and ensifentrine $(10 \mu \mathrm{M})$ in either non-stimulated conditions or after cells were prestimulated with PF $(500 \mathrm{nM}){ }^{* *}$ significant effect vs DMSO in non-stimulated conditions $(\mathrm{p}<0.01$; $* * * \mathrm{p}<0.001)$. $†$ Significant effect of PF prestimulation $(\mathrm{p}<0.05)$. Data represents mean \pm S.D., $\mathrm{n}=3-9 ; \mathrm{N}=2$. (D) summary of the effect of PDE pre-stimulation on the $I_{s c}$ responses to PF (500 nM). Mean \pm S.D., $n=4-6$; $\mathrm{N}=2$. * Significant effect of prestimulation by roflimulast or ensifentrine $(\mathrm{p}<0.05 ; * * \mathrm{p}<0.01)$. 
by the donor mTurquoise 2 and the tandem repeat acceptor Venus [36]. With this probe, increased $[\mathrm{cAMP}]_{\mathrm{i}}$ is detected by measuring the fluorescence lifetime of the FRET donor mTurquoise 2 as a readout for reduced FRET. Fig. 6B shows typical images collected during experiments. Fig. $6 \mathrm{C}$ summarizes the effect of cAMP agonists on mTurquoise 2 lifetime.

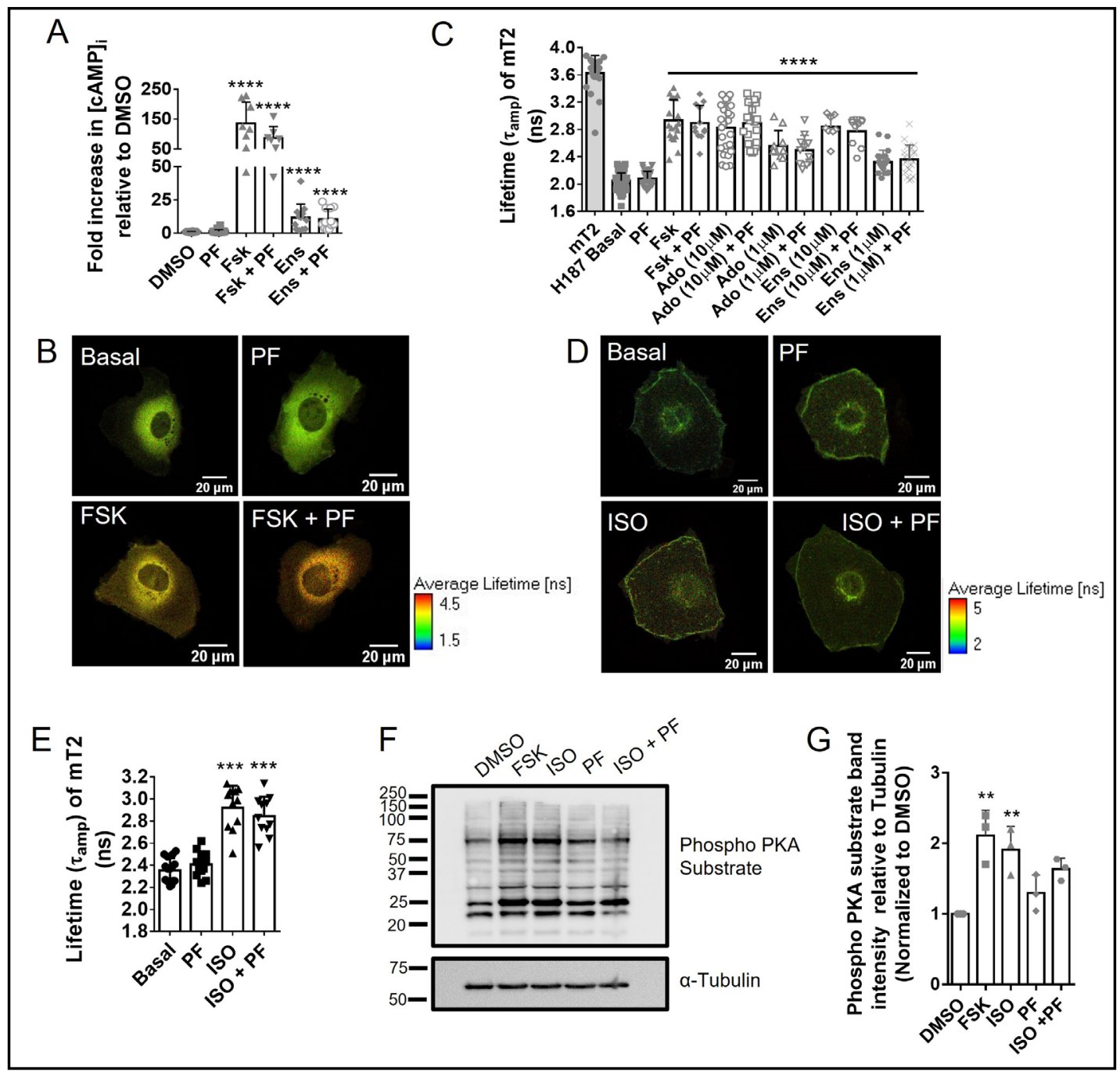

Fig. 6. PDE8 inhibition does not increase global cAMP levels measurably in CFBE41o- WT cells. (A) Welldifferentiated CFBE41o- WT cells were treated for 15 min with vehicle (0.1\% DMSO), PF (500 nM), forskolin (Fsk; $2 \mu \mathrm{M})$, Fsk + PF, ensifentrine (Ens; $10 \mu \mathrm{M}$ ) or Ens + PF. Cells were then lysed and [cAMP] $]_{i}$ quantified by ELISA. [cAMP] $]_{i}$ was normalized to intracellular protein concentration (pmol cAMP per mg of cellular protein) and each treatment condition was normalized to DMSO treated cells. ${ }^{* * * *}=$ significant increase vs. DMSO treated control cells $(\mathrm{p}<0.0001)$. Data represents mean \pm S.D., $n=7-20$; N=3-4. (B) Representative FAST-FLIM images from CFBE41o- WT cells expressing EPAC-S ${ }^{\mathrm{H} 187}$ stimulated with PF (500 nM), forskolin (FSK; $2 \mu \mathrm{M})$ and forskolin + PF. (C) summary of the effect of each agonist on mTurquoise2 lifetime. ${ }^{* * *}=$ significant increase in mT2 lifetime vs basal conditions. Data represents mean \pm S.D., $n=8-88 ; N=2-11$. (D) Representative FAST-FLIM images in CFBE410- WT cells expressing Lyn-EPAC-S ${ }^{\mathrm{H} 187}$ stimulated with PF (500 $\mathrm{nM}$ ), isoproterenol (ISO; $1 \mu \mathrm{M}$ ) and isoproterenol + PF. (E) summary of the effect of each agonist on mTurquoise 2 lifetime. ${ }^{* * *}=$ significant increase in mT2 lifetime vs basal conditions $(\mathrm{p}<0.001)$. Data represents mean \pm S.D., $n=12$-16; $N=2$. (F) Representative immunoblot demonstrating effect of PF (500nM), forskolin (FSK; $2 \mu \mathrm{M}$ ), and isoproterenol (ISO; $1 \mu \mathrm{M}$ ) on phosphorylation of PKA substrates. (G) summarizes fold changes in band intensity measured by densitometry and normalized to that of $\alpha$-tubulin. Mean \pm S.D., N=3.

** significant effect vs DMSO $(\mathrm{p}<0.01)$. 


\section{Cellular Physiology Cell Physiol Biochem 2021;55:784-804 \\ \begin{tabular}{ll|l} 
and Biochemistry & $\begin{array}{l}\text { DOl: 10.33594/000000477 } \\
\text { Published online: } 23 \text { December } 2021\end{array}$ & $\begin{array}{l}\text { C } 2021 \text { The Author(s). Published by } \\
\text { Cell Physiol Biochem Press GmbH\&Co. KG }\end{array}$
\end{tabular} \\ Turner et al.: Phosphodiesterase 8A Regulates CFTR Activity}

PF did not change the fluorescence lifetime of mTurquoise 2 when compared with untreated cells ( $2.08 \pm 0.02 \mathrm{~ns}$ vs $2.05 \pm 0.01 \mathrm{~ns} ; \mathrm{n}=31-88, \mathrm{~N}=5-7 ; \mathrm{p}>0.05)$ indicating [cAMP] $]_{\mathrm{i}}$ was not increased, in contrast to forskolin, adenosine and ensifentrine, which induced significant increases in $[\mathrm{CAMP}]_{i}$ that were not further enhanced by PF. FRET-FLIM measurements were also made in cells using a modified EPAC- $\mathrm{S}^{\mathrm{H} 187}$ that was targeted to the membrane by N-terminal fusion of a Lyn tyrosine kinase sequence. However, targeting the FRET-FLIM sensor to the plasma membrane did not produce measurable PF-induced changes in the fluorescence lifetime of mTurquoise 2 in control or isoproterenol-stimulated cells (Fig. 6D-6E). These results indicate that any increases in cAMP due to PF are below the detection threshold for the FRET sensor. As an alternative method for detecting of cAMP/PKA signalling, we tested whether PKA-dependent protein phosphorylation is broadly increased by PDE8 inhibition by probing immunoblots using an antibody that detects phosphorylated serine and threonine residues with arginine at the -3 and -2 positions (RRXS*/T*) as occurs in dibasic consensus PKA sites. A representative immunoblot is shown in Fig. 6F. Densitometry confirmed that forskolin and isoproterenol both caused significant phosphorylation of PKA substrates whereas PF did not (Fig. 6G). These data are consistent with the ELISA experiments and confirm that PF does not cause a detectable increase in global [CAMP $]_{\mathrm{i}}$ in CFBE41o- WT cells.

Inhibiting PDE8 stimulates CFTR-dependent $I_{s c}$ in CFBE41o-WT cells

Although PF did not increase [CAMP] measurably in CFBE41o- WT cells, CFTR activation was detectable at $300 \mathrm{nM} \mathrm{PF}$ and was further increased at higher concentrations (Fig. 7A and 7B). At $500 \mathrm{nM}$, the PF stimulation was highly significant ( $4.69 \pm 0.50 \mu \mathrm{A} \mathrm{cm}{ }^{-2} ; \mathrm{n}=18 ; \mathrm{N}=5$; $\mathrm{p}<0.001$ vs. DMSO) and sensitive to $\mathrm{CFTR}_{\text {inh }}-172$ (Fig. 7C). We next assessed the effect of inhibiting PDE8 in cells pre-stimulated with forskolin, isoproterenol or adenosine (Fig. 7D$7 F)$. Forskolin caused the largest increase in $\mathrm{I}_{\mathrm{sc}}\left(61.84 \pm 2.63 \mu \mathrm{A} \mathrm{cm}^{-2} ; \mathrm{n}=13, \mathrm{~N}=3\right)$ followed by isoproterenol $\left(34.04 \pm 3.38 \mu \mathrm{A} \mathrm{cm}^{-2} ; \mathrm{n}=13, \mathrm{~N}=3\right)$ and adenosine $\left(22.18 \pm 1.76 \mu \mathrm{A} \mathrm{cm}^{-2}\right.$; $\mathrm{n}=13, \mathrm{~N}=3$ ), similar to results with well-differentiated pHBE cells (compare summary in Fig. $7 \mathrm{G}$ with Fig. 3E). PF responses were inversely proportional to the prestimulation; i.e. acute $\mathrm{PF}$ responses were largest after adenosine, intermediate after isoproterenol, and smallest after forskolin (Fig. 7H). We also compared the effects of different PDE inhibitors on unstimulated CFBE410- WT cells. Milrinone had no effect whereas roflimulast and ensifentrine both produced robust CFTR-dependent currents that were larger than those elicited by sildenafil and PF (Fig. 7I). These results indicate there is substantial cAMP production in CFBE410WT cells under control conditions which is mostly degraded by PDE4.

PDE8 inhibition increases $I_{\text {sc }}$ by direct activation of CFTR at the apical membrane

The functional responses in CFBE41o- WT made it possible to localize the effects of PF. We measured $\mathrm{I}_{\mathrm{sc}}$ while permeabilizing the basolateral membrane in the presence of a reversed transepithelial $\mathrm{Cl}^{-}$gradient (i.e. from basolateral-to-apical to apical-to-basolateral to minimize cell swelling). Nystatin produced a negative $\mathrm{I}_{\mathrm{sc}}$ of $25.78 \pm 3.78 \mu \mathrm{A} \mathrm{cm}^{-2}(\mathrm{p}<0.001 \mathrm{vs}$. control; $\mathrm{n}=24 ; \mathrm{N}=4)$, as expected when transepithelial $\mathrm{Cl}$ - flux is rate-limited by the conductance of the apical membrane (Fig. 8A). PF stimulated an $\mathrm{I}_{\mathrm{sc}}$ of $33.72 \pm 9.62 \mu \mathrm{A} \mathrm{cm}^{-2}(\mathrm{n}=3-9$; $\mathrm{N}=3$; Fig. 8B) demonstrating that it acts at the apical membrane. Basolateral permeabilization increased the response to PF more than to forskolin or ensifentrine suggesting those treatments may normally raise [cAMP $]_{i}$ sufficiently to activate basolateral $\mathrm{K}^{+}$channels $[42,43]$. In support of this interpretation, pre-treating unpermeabilized cells with the KCNQ1 inhibitor Chromanol 293B caused a small decrease in forskolin-stimulated $\mathrm{I}_{\mathrm{sc}}$ but had no effect on the response to PF (Fig. 8C). Together, these data demonstrate that PDE8 inhibition causes a localized activation of CFTR at the apical membrane of airway epithelia. 
Fig. 7. PDE8 inhibition stimulates CFTR-dependent $\mathrm{I}_{\mathrm{sc}}$ in CFBE41o- WT cells. Polarized, well differentiated CFBE410- WT cells were mounted in Ussing chambers and $\mathrm{I}_{\mathrm{sc}}$ was measured. (A) shows representative trace demonstrating effect of increasing PF concentration on $\mathrm{I}_{\mathrm{sc}}$ (B) displays the concentration-response curve. ${ }^{*}$ Significant increase in $\mathrm{I}_{\mathrm{sc}}\left(\mathrm{p}<0.05 ;{ }^{* *} \mathrm{p}<0.01\right.$; *** $\mathrm{p}<0.001)$. Data represents mean \pm S.D.; $n=10$; $N=3$. (C), (D), (E) and (F) show representative traces demonstrating effect of PF (500nM) in basal, adenosine $(10 \mu \mathrm{M})$, isoproterenol $(1 \mu \mathrm{M})$ and forskolin $(2 \mu \mathrm{M})$-stimulated

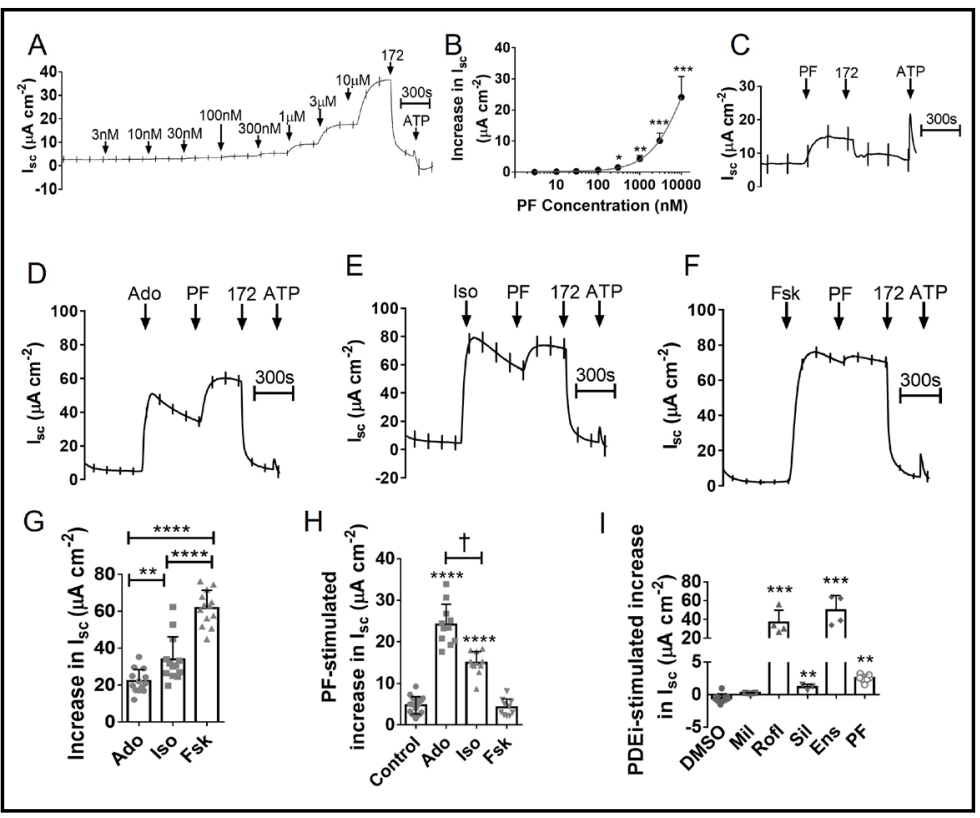
cells respectively. (G) summary of the increases in $I_{s c}$ produced by each cAMP agonist $* * * *$ significant between Iso vs Fsk and Ado vs Fsk $(\mathrm{p}<0.0001) * *$ significant between Ado vs Iso $(\mathrm{p}<0.01)$ Data represents mean \pm S.D..; $n=13 ; \mathrm{N}=4$. (H) summary of the increase in $\mathrm{I}_{\mathrm{sc}}$ produced by $\mathrm{PF}$ after pre-stimulation. ${ }^{* * * *}$ significant vs control (i.e. no pre-stimulation) $(\mathrm{p}<0.0001) \dagger$ significant between Ado vs Iso $(p<0.0001)$. Data represents mean \pm S.D..; $n=10-11 ; N=4$. (I) summary of the increase in $I_{s c}$ produced by PDE inhibitors milrinone (Mil; $10 \mu \mathrm{M}$ ), roflimulast (Rofl; $1 \mu \mathrm{M}$ ), sildenafil (Sil; $10 \mu \mathrm{M}$ ) ensifentrine (Ens; $10 \mu \mathrm{M})$ and PF (500 nM). Mean \pm S.D..; $\mathrm{n}=3-9$; $\mathrm{N}=2 .{ }^{* *}$ significant vs DMSO $\left(\mathrm{p}<0.01 ;{ }^{* * *} \mathrm{p}<0.001\right)$.

Fig. 8. PF stimulates $\mathrm{I}_{\mathrm{sc}}$ by activating apical CFTR-dependent $\mathrm{Cl}^{-}$ secretion. Polarized, well differentiated CFBE41o- WT cells were mounted in Ussing chambers and $I_{s c}$ was measured. (A) shows a typical recording during permeabilization of the basolateral membrane by Nystatin (Nys; $200 \mu \mathrm{g} \mathrm{ml}^{-1}$ ). Cells were subsequently exposed to PF (500 nM), CFTR $_{\text {inh }}-172(172 ; 10 \mu \mathrm{M})$ and ATP $(100 \mu \mathrm{M})$ to confirm viability. (B) summary of $\mathrm{I}_{\mathrm{sc}}$ responses with and without permeabilization of the basolateral membrane when exposed to PF, forskolin (Fsk; $2 \mu \mathrm{M}$ ) and ensifentrine $(10 \mu \mathrm{M})^{* *}=$ significant effect of permeabilization $(\mathrm{p}<0.05 ; * * * *=\mathrm{p}<0.0001)$. Data represents mean \pm S.D., $n=3-10$; $N=3$. (C) effect of pretreating cells with Chromanol 293B $(20 \mu \mathrm{M})$ on the $\mathrm{I}_{\text {sc }}$ response to PF (500 nM) and forskolin $(2 \mu \mathrm{M})$. Mean \pm S.D., $\mathrm{n}=10-12 ; \mathrm{N}=3$. * Effect of Chromanol 293B ( $\mathrm{p}<0.05)$.

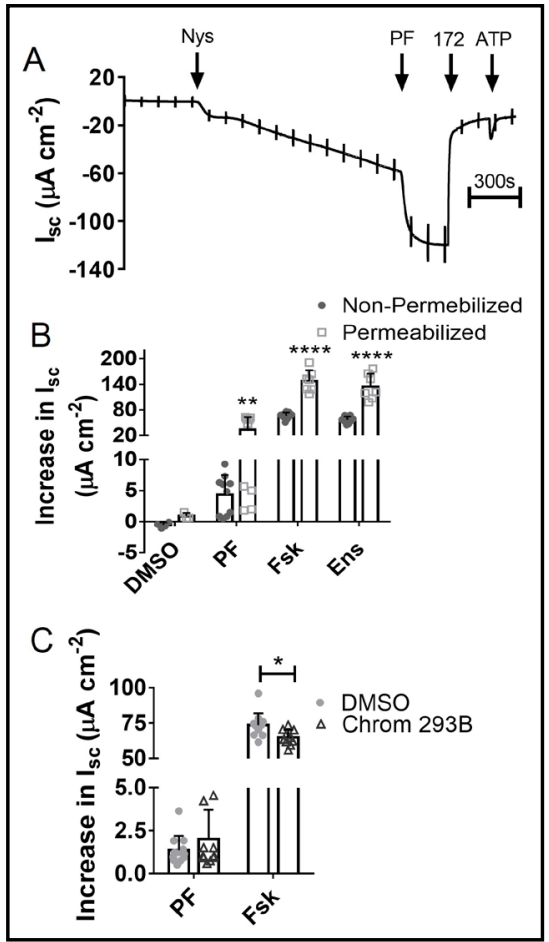




\section{Cellular Physiology Cell Physiol Biochem 2021;55:784-804 \begin{tabular}{ll|l} 
and Biol: 10.33594/000000477 & C 2021 The Author(s). Published by \\
Cell Physiol Biochem Press GmbH\&Co. KG
\end{tabular}

\section{MRP4 influences PDE4- but not PDE8-regulated cAMP signalling}

Several multidrug resistance proteins export cyclic nucleotides and one of these, MRP4, was implicated in the regulation of CFTR in the intestine when Mrp4 knockout mouse were found to have increased susceptibility to cAMP-induced secretory diarrhoea [44]. To examine the impact of MRP4 on $\mathrm{I}_{\mathrm{sc}}$ responses to PDE inhibitors, CFBE41o- WT cells were treated sequentially with vehicle or the MRP4 inhibitor ceefourin1 (20 $\mu \mathrm{M}$ [45]) followed by PF $(500 \mathrm{nM})$ or ensifentrine $(1 \mu \mathrm{M})$ (Fig. 9A, B). Ceefourin 1 alone did not increase basal $I_{s c}$, suggesting there is little if any MRP4-dependent cAMP efflux under control conditions (Fig. 9A, B). The response to PF was also unaffected by ceefourin1 whereas stimulation by ensifentrine was increased $>50 \%$ (Fig. 9C). These results show that MRP4 modulation of functional responses to cAMP e.g. CFTR-dependent $\mathrm{I}_{\text {sc, }}$ depends on the PDE inhibitor used and does not suppress the response to PF.

\section{PDE8A knockdown using CRISPR Cas9 reduces PF stimulation of CFTR}

If the stimulation by PF results from inhibition of PDE8A, it should be reduced by knockdown of PDE8A expression. To test this prediction, CFBE41o- WT cells were cotransfected with CRISPR gRNA targeting PDE8A and Cas 9 as described in the Methods and clones were selected. One clone had a $64 \pm 3 \%$ reduction in PDE8A mRNA according to qPCR (Fig. 10A) and $89 \pm 5 \%$ reduction in protein expression in immunoblot when compared to the negative control ( $\mathrm{p}<0.0001 ; \mathrm{N}=3$; Fig. 10A-10C). PDE8A knockdown strongly inhibited the $\mathrm{I}_{\mathrm{sc}}$ response to PF under both basal and adenosine-stimulated conditions (Fig. $10 \mathrm{D}-10 \mathrm{H}$ ), supporting the conclusion that PF effects are mediated by inhibition of PDE8A. CFTR expression was increased by CRISPR gene editing in both scrambled control and PDE8A knockdown cells (see Fig. 10A-10B). This unexpected off-target effect strengthens the conclusion that PDE8A mediates the effects of PF on $\mathrm{I}_{\mathrm{sc}}$ since responses were reduced relative to negative and scrambled controls despite increased CFTR expression.

\section{PDE8A inhibition increases activation of rescued F508del/F508del CFTR in pHBE cells}

Having shown that PDE8A regulates wild-type CFTR in both pHBE and CFBE41o- cells, we next examined the efficacy of PDE8A inhibition after partial rescue of mutated CFTR using clinically approved modulators. Well-differentiated pHBE cells from two F508del homozygous patients were treated with vehicle or the modulators VX-445 + VX-661 + VX-770 for $24 \mathrm{~h}$ to mimic the clinically approved drug Trikafta ${ }^{\mathrm{TM}}[46,47]$. Forskolin and isoproterenol did not alter $I_{s c}$ when cells were pre-treated with vehicle but did cause stimulation when cells were pretreated with CFTR modulators, consistent with partial rescue of F508del CFTR (Fig. 11A, B, D, E). For patient $A, \mathrm{PF}$ enhanced forskolin- and isoproterenol-stimulated $\mathrm{I}_{\mathrm{sc}}$ responses to the same level as roflumilast and both PDE inhibitors had more pronounced

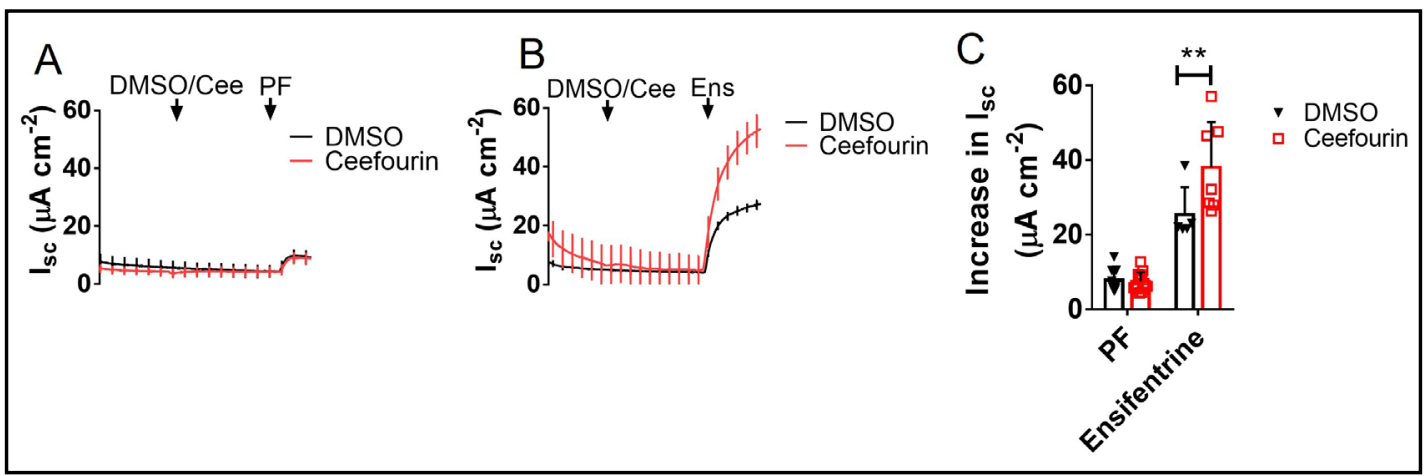

Fig. 9. MRP4 inhibition modulates PDE4 but not PDE8-dependent cAMP signalling. (A) and (B) Representative traces in which CFBE410- WT cells were mounted in Ussing Chambers and treated with either vehicle (DMSO) or ceefourin $1(20 \mu \mathrm{M})$ prior to acute stimulation with either PF (500 nM) or ensifentrine $(1 \mu \mathrm{M})$. (C) summary of the effect of ceefourin on the response to PDE inhibitor. Mean \pm S.D., $n=5-14 ; N=3$. ${ }^{* *} p<0.01$. 
Fig. 10. PDE8A knockdown in CFBE41o- WT cells attenuates stimulation of CFTR by PF. CFBE410- WT cells transfected with Cas9 and CRISPR gRNA targeting PDE8A or Scrambled and cultured from single clones to generate a stable cell population. Cells were studied on transwell inserts after 1 week of airliquid interface culture. (A) expression of PDE4D, PDE8A and CFTR mRNA in negative control (no gRNA and Cas9 expression), Scrambled gRNA and PDE8A gRNA expressing cells after normalizing to GAPDH. *** significant effect of PDE8A knockdown $(p<0.001)$. Data represents mean \pm S.D., $\mathrm{N}=3$ (B) representative immunoblot show-

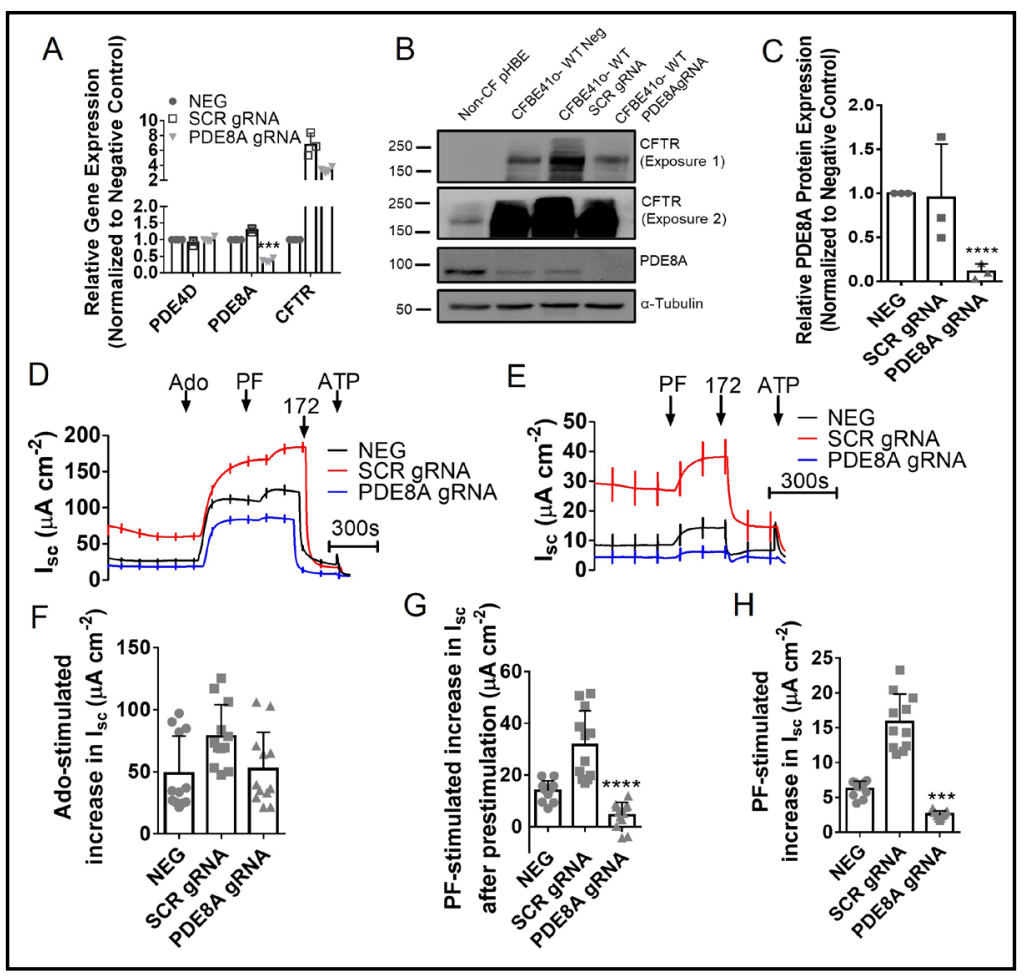
ing PDE8A and CFTR protein expression in non-CF pHBE and CRISPR Ca9 CFBE410- WT cells. (C) summary of the protein expression when normalized to $\alpha$-tubulin expression. ${ }^{* * * *}$ significant effect of PDE8A knockdown $(\mathrm{p}<0.0001)$ Data represents mean \pm S.D., $N=3$. (D) and (E) representative traces showing stimulation of $\mathrm{I}_{\mathrm{sc}}$ in CRISPR Cas9 CFBE41o- WT cells by adenosine (Ado; $10 \mu \mathrm{M})$ and PF (500nM) or PF alone respectively. (F) summarizes the stimulation of $I_{s c}$ by Ado. Data represents mean \pm S.D., $n=12$; $N=3$. (G) summarizes the stimulation of $I_{s c}$ by PF in Ado pre-stimulated cells. ${ }^{* * * *}$ significant effect of PDE8A knockdown $(\mathrm{p}<0.0001)$. Data represents mean \pm S.D., $n=12 ; N=3$. (H) summarizes the stimulation of $I_{s c}$ by $P F$ under basal conditions. Mean \pm S.D., $n$ $=11 ; \mathrm{N}=3{ }^{* * * *}$ significant effect of PDE8A knockdown $(\mathrm{p}<0.0001)$.

effects after stimulation by isoproterenol compared to forskolin (Fig. 11C). CFTR modulators were less efficacious in cells from patient $B$, and neither PF nor roflumilast enhanced forskolin-stimulated $I_{s c}$ (Fig. 11D). Surprisingly, the increase in isoproterenol-stimulated $I_{s c}$ was larger with $\mathrm{PF}$ than with roflumilast despite roflumilast inducing larger effects in non-CF cells (Fig. 4). These results confirm the variation between individuals in responsiveness to corrector drugs [48] and indicate that PDE8A inhibitors may be beneficial for the treatment of F508del/F508del patients when combined with CFTR modulators.

\section{PDE8A inhibition stimulates CFTR activity in F508del/R117H-5T pHBE cells}

In previous studies we showed that ensifentrine increases the activity of CFTR class III (gating) and class IV (permeation) mutants in Fisher rat thyroid cells and the class IV mutant R117H endogenously expressed in pHBE cells $[16,20]$. To examine the effect of PDE8 inhibition on R117H CFTR, pHBE cells from a CF patient with the genotype F508del/R117H5T were differentiated at the air-liquid interface, treated with the CFTR modulators VX-809 and VX-770 for $24 \mathrm{~h}$, and then studied in Ussing Chambers (Fig. 12A-B). F508del/R117H-5T cells did not respond to PF alone ( $I_{s c}$ increase: $-0.15 \pm 0.07 \mu \mathrm{A} \mathrm{cm}^{-2} ; \mathrm{p}>0.05$ vs. DMSO; $\mathrm{n}=4$, $\mathrm{N}=1$; Fig. 12C); however, $\mathrm{PF}$ did increase $\mathrm{I}_{\mathrm{sc}}$ by $2.17 \pm 0.24 \mu \mathrm{A} \mathrm{cm}^{-2}$ in F508del/R117H-5T cells that had been pretreated with forskolin ( $p<0.001$ vs. DMSO; $n=3, N=1$; Fig. 12C). These results demonstrate that PDE8A inhibition enhances the activation of mutant CFTR (F508del/R117H-5T) after partial rescue by CFTR modulators, encouraging development of PDE8A inhibitors as an adjunct therapy for CF. 
Fig. 11. CFTR modulators restore cAMP-stimulated F508del CFTR activity which is further potentiated by PDE8 inhibition. Well-differentiated pHBE cells isolated from two F508del/ F508del patients were pretreated for $24 \mathrm{~h}$ with the CFTR modulators VX-445 $(3 \mu \mathrm{M})$, VX$661(3 \mu \mathrm{M})$ and VX-770 (10 nM) before being mounted in Ussing Chambers for measurements of Isc. (A) and (D) show representative traces for two different patients. Cells were treated with apical amiloride (Amil; $100 \mu \mathrm{M}$ ) before cAMP stimulation with

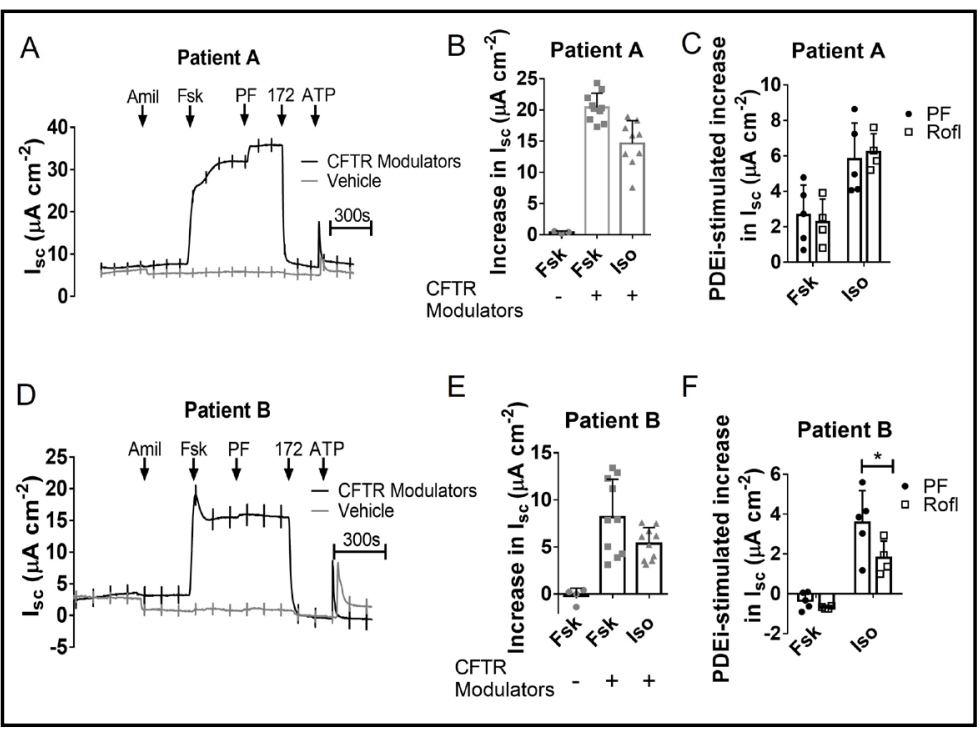
either forskolin (FSK; $2 \mu \mathrm{M}$ ) or isoproterenol (ISO; $1 \mu \mathrm{M}$ ) and addition of PDE inhibitors PF (500nM) or roflumilast $(1 \mu \mathrm{M})$. CFTR $_{\text {inh }}-172(172 ; 10 \mu \mathrm{M})$ was added to test if $\mathrm{I}_{\mathrm{sc}}$ was CFTR-dependent before ATP $(100 \mu \mathrm{M})$ was added at the end of each experiment to confirm that the cells were functional. (B) and (E) summarizes the effect of CFTR modulators on cAMP-stimulated CFTR activity in each patient respectively. Data represents mean \pm S.D., $n=4-10$. (C) and (F) summarizes the effect of PF or Rofl on forskolin and isoproterenol-stimulated cells that had been pre-treated with CFTR modulators. Mean \pm S.D., $n=4-5$. ${ }^{*}$ Significant difference between PF and Rofl in isoproterenol-stimulated cells $(\mathrm{p}<0.05)$.

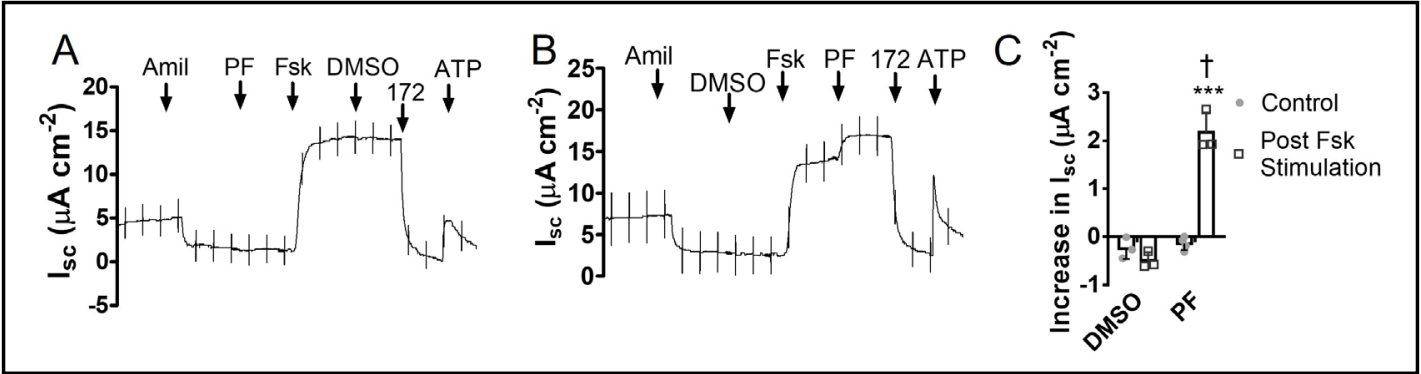

Fig. 12. Inhibiting PDE8 stimulates CFTR-dependent $I_{s c}$ in forskolin-stimulated F508del/R117H-5T primary HBE cells. Well-differentiated pHBE cells isolated from one F508del/R117H-5T patient were pretreated for $24 \mathrm{~h}$ with the CFTR modulators VX-809 $(1 \mu \mathrm{M})$ and VX-770 $(10 \mathrm{nM})$ before being mounted in Ussing Chambers for measurements of Isc. (A) and (B) show representative traces showing cells stimulated with PF $(500 \mathrm{nM})$ under basal conditions or after pre-stimulation with forskolin Fsk $(2 \mu \mathrm{M})$. (C) summarizes the Isc responses to PF. Data are means \pm S.D., $n=3-4 .{ }^{* * *}$ significant vs vehicle in Fsk-stimulated cells $(\mathrm{p}<0.001)$; $\dagger$ significant effect of Fsk pre-stimulation $(\mathrm{p}<0.001)$.

\section{Discussion}

In the present study we have demonstrated robust expression of PDE8A in welldifferentiated human airway epithelial cells and provided the first evidence that it regulates CFTR channel activity. Acute inhibition enhances the stimulation of F508del CFTR and R117H CFTR channel activity after partial rescue by CFTR modulators, suggesting PDE8A as a potential target for $\mathrm{CF}$ therapeutics. 
Several physiological functions have been proposed for PDE8 since it was first reported in 1998 [49]. It co-immunoprecipitates with Raf-1, a component of the MEK-ERK signalling pathway, and has been proposed to suppress Raf-1 phosphorylation by maintaining low cAMP levels [50]. It regulates effector $\mathrm{T}$ cell $\left(\mathrm{T}_{\text {eff }}\right)$ attachment to the vascular endothelium in response to injury [26], and regulation of cAMP-stimulated, $\mathrm{Ca}^{2+}$-dependent contraction in ventricular myocytes has been suggested based on studies of PDE8A knock-out mice [28]. PDE8 inhibition reduces breast cell cancer migration, implicating it in breast cancer metastasis [29]. It has been studied in airway smooth muscle and suggested as a potential drug target in asthma [33]. The present work, for the first time, indicates a role CFTR regulation in airway epithelial cells.

\section{PDE8 regulates CFTR in $\mathrm{pHBE}$ cells}

[CAMP $]_{\mathrm{i}}$ was elevated in well-differentiated pHBE cells by exposure to the PDE8 inhibitor PF-04957325 (PF) under basal conditions (Fig. 2) and this increase was accompanied by stimulation of CFTR (Fig. 3). Thus, PDE8 regulates basal cAMP levels and helps maintain CFTR in a quiescent state in resting cells. Basal [cAMP $]_{i}$ has not been measured in pHBE cells however it is estimated to be $\sim 1 \mu \mathrm{M}$ in CHO cells based on the FRET-based PKAactivity reporter AKAR3 [51]. A role of PDE8A under basal conditions fits well with its 45-fold higher affinity for cAMP compared to human PDE4D [25], which is the dominant enzyme regulating cAMP-dependent CFTR activity in pHBE cells as evidenced by the large increases in $[\mathrm{CAMP}]_{\mathrm{i}}$ and stimulation of CFTR produced by roflumilast and ensifentrine (Fig. 2,4 and 5). PDE8A does not appear functionally coupled to the $\beta_{2}$ adrenergic receptor as the elevation of $[\mathrm{cAMP}]_{\mathrm{i}}$ induced by isoproterenol was not potentiated by PF. This contrasts with $\beta_{2}$ adrenergic receptor signalling in human airway smooth muscle cells [33], and in ventricular myocytes from PDE8A knockout mice where alterations in cAMP levels are only detected during isoproterenol stimulation [28]. In the present study, inhibiting PDE8A enhanced isoproterenol stimulated CFTR-dependent currents to a greater extent than forskolin or adenosine (Fig. 3), consistent with compartmentalized regulation of CFTR by local $\beta_{2}$ adrenergic receptors and PDE8A that did not correspond with measured changes in global $[\mathrm{CAMP}]_{\mathrm{i}}$. A discrepancy between $[\mathrm{cAMP}]_{\mathrm{i}}$ and CFTR responses was noted previously in Calu-3 cells, where adenosine and forskolin caused similar activation of CFTR despite 9-fold higher [CAMP] during forskolin stimulation [52]. In summary PDE8A suppresses CFTR activity in both basal conditions and when activated by low levels of cAMP induced by physiological agents.

When pHBE cells were stimulated with cAMP-elevating agents, PF enhanced CFTR activity more than milrinone or sildenafil (Fig. 4) but less than roflimulast and ensifentrine, confirming PDE4 as the predominant PDE regulating CFTR in pHBE cells $[16,17,39,53]$. Interestingly, PDE8 inhibition enhanced the response to PDE4 inhibitors and vice versa (Fig. 5). PDE4 and PDE8A are both activated by PKA phosphorylation [54], therefore inhibiting one PDE may promote phosphorylation and activation of the other. Synergism between PDE4 and PDE8 inhibitors has been reported for cAMP-regulated testosterone production in Leydig cells and progesterone synthesis in MA-10 cells [31, 55] while PDE4 and PDE8 inhibitors produce synergistic phosphorylation of many proteins in Leydig cells [56]. The PDE4 and PDE8 relationship is intriguing and studies into dual PDE4/8 inhibitors, such as those described by Demirbas, et al. [55] would provide further insights into the role of these two PDEs in bronchial epithelia.

PDE8 expression and function in CFBE41o- WT cells

We examined CFBE41o- WT cells as a model for studying CFTR regulation by PDEs, although PDE8A expression is lower than in well differentiated pHBE cells (Fig. 1). Inhibiting PDE8Adid not cause a measurable increase in either global or membrane-associated cAMP nor did it induce significant phosphorylation of proteins that possess PKA consensus sequences in CFBE41o- WT cells (Fig. 6). However, the high sensitivity of electrophysiological methods allowed detection of PF-stimulated CFTR-dependent currents (Fig. 7). $\mathrm{I}_{\mathrm{sc}}$ responses to PF 
were similar in pHBE cells and CFBE41o- WT cells (compare Fig. 3E and 7G) suggesting that high CFTR expression in CFBE41o- cells after lentiviral transduction helps offset lower PDE8 expression in this cell line. Regardless, PF enhanced adenosine-stimulated $\mathrm{I}_{\mathrm{sc}}$ in CFBE41oWT cells and the effect was more pronounced than when PF was added after isoproterenol, opposite to responses in pHBE cells (compare Fig. 7H and 3F) and airway smooth muscle [33]. Differences between pHBE and CFBE41o- WT cells were also observed for cAMP levels during forskolin stimulation of CFBE41o- WT compared to pHBE cells consistent with the results of Monterisi, et al. [57], who ascribed the difference to cytoskeletal organization. This may also contribute to altered responses to PF in pHBE cells compared to CFBE41ocells while differences in PDE8A colocalization with adenosine and $\beta$-adrenergic receptors or altered receptor densities and/or adenylyl cyclase expression could also be important factors. Furthermore, the heterogeneity of differentiated HBE cells [58-60] may confer co-expression of CFTR with PDE8A in distinct cell types that are not present in the clonal CFBE41o- cell line.

CFTR is localized in a macromolecular complex with the $\beta_{2} \mathrm{AR}$ and multidrug resistance protein-4 (MRP4), which can export cAMP and many other substrates [61, 62]. PDE8A colocalizes with $\beta_{2} A R$ in human smooth muscle cells [33] and may also be present in epithelial cell microdomains in together with MRP4. These proteins regulate local cAMP over very different concentration ranges. The MRP4 inhibitor ceefourin1 had no effect on $I_{s c}$ when added alone and therefore probably has little effect on basal cAMP levels (Fig. 9). Ceefourin 1 also did not enhance the response to PF, probably because MRP4 is not active at the low cAMP concentrations degraded by PDE8A $(\mathrm{Km}=55 \mathrm{nM})$. The 800 -fold lower affinity of MRP4 for cAMP ( $\mathrm{Km}=45 \mu \mathrm{M}$ [63]) suggests that it would only influence CFTR activity when cAMP levels are elevated. The $I_{\text {sc }}$ response to ensifentrine was increased $>50 \%$ by pretreating cells with ceefourin1, therefore PDE4 inhibition is apparently sufficient to raise cAMP concentration into a range where MRP4 activity becomes significant (Fig. 9B, C). These results are congruent with MRP4-dependent cAMP efflux from leukaemia cells, which only becomes significant during agonist stimulation [64]. A caveat of inferences based on $\mathrm{Km}$ is that enzyme kinetics are determined in vitro may differ in cells [51], nevertheless PDE8A results are compatible with current models for regulation by compartmentalized cAMP signaling.

The PF-induced increase in $\mathrm{I}_{\text {sc }}$ was due to apical CFTR channels activation as it did not depend on basolateral conductances involved in transepithelial secretion (Fig. 8). In human airway epithelia, the intermediate conductance $\mathrm{Ca}^{2+}$-activated $\mathrm{K}^{+}(\mathrm{KCa} 3.1)$ channel hyperpolarizes epithelial cells and contributes to the electromotive force driving apical anion efflux $[65,66]$ and cAMP-regulated $\mathrm{K}^{+}$channels formed by KCNQ1/KCNE3 subunits contribute to efficient cAMP-stimulated anion secretion in human airway epithelia [42, 43]. However, the PF stimulation persisted after permeabilization of the basolateral membrane and was unaffected by inhibiting KCNQ1/KCNE3 (Fig. 8). We generated a PDE8A knockdown CFBE41o- cell line using CRISPR-Cas9 and found strong inhibition of the $\mathrm{I}_{\mathrm{sc}}$ response to PF under both basal and adenosine-stimulated conditions despite increased CFTR expression (Fig. 10). Those results support the conclusion that PF effects are mediated by inhibition of PDE8A, although we cannot exclude other off-target effect induced by gene editing such as reduced $\mathrm{A}_{2} \mathrm{~B}$ receptor expression. Similarly, we cannot rule out off-target pharmacological effects on other enzymes, especially at the highest PF concentrations tested where some inhibition of other PDEs is likely (3-10 $\mu \mathrm{M}$; Fig. 7A, B). However, the PF concentration used routinely in experiments $(500 \mathrm{nM})$ was lower than in previous studies and should provide good selectivity for PDE8 [26, 29, 33, 67].

PDE8 inhibitors may provide benefit for CF patients when used in combination with CFTR modulators (Fig. 10-11). PF was surprisingly effective in stimulating $\mathrm{I}_{\mathrm{sc}}$ across F508del/F508del pHBE cells after pretreatment with CFTR modulators (comparable to the PDE4 inhibitor roflumilast) and enhanced stimulation by isoproterenol, in agreement with previous studies [17]. PF also enhanced activation of endogenously expressed R117H-CFTR channel in pHBE that had been pretreated with CFTR modulators. These results identify 


\section{Cellular Physiology Cell Physiol Biochem 2021;55:784-804

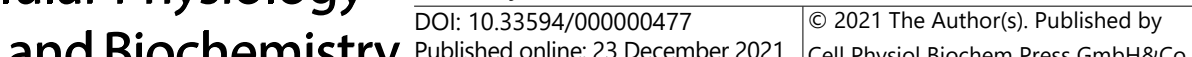 \\ Published online: 23 December 2021 Cell Physiol Biochem Press GmbH\&Co. KG \\ Turner et al.: Phosphodiesterase 8A Regulates CFTR Activity}

PDE8 inhibitors as novel therapeutics for CF treatments while the synergistic effects of PDE4 and PDE8 inhibitors on wild-type CFTR activity suggest that dual PDE4/8 inhibitors could be particularly effective.

We recently showed that ensifentrine downregulates pro-inflammatory mediators in CF lung airway epithelial cells mainly through inhibition of PDE4 [68], suggesting PDE4 inhibitors could have beneficial effects on both inflammation and CFTR function. It would be interesting to explore anti-inflammatory effects of PDE8 inhibitors in airway epithelium. PDE8 inhibition reduces $T$ cell migration and adhesion and therefore may play a role in cytokine production by those cells $[26,27]$. Roflumilast reduces airway inflammation and has immunomodulatory benefits in COPD which may include CFTR stimulation as COPD is associated with an acquired CFTR deficiency $[69,70]$. Development of an aerosolized dual PDE4/8 inhibitor could have improved efficacy for COPD, CF, and other inflammatory lung disease.

\section{Conclusion}

In summary, we have identified PDE8 as a novel regulator of cAMP-stimulated CFTRdependent anion secretion in primary human bronchial airway epithelial cells. Inhibiting PDE8 enhances basal and $\beta$-adrenergic stimulation of mutant CFTR in CF pHBE cells carrying the $c f t r$ genotypes R117H-5T/F508del and F508del/F508del after partial rescue by Trikafta. These results suggest that PDE8 and PDE4 are both important for controlling CFTR activity in well differentiated HBE cells and encourage development of a dual PDE4/PDE8 inhibitor for the treatment of COPD and CF.

\section{Abbreviations}

[cAMP $_{\mathrm{i}}$ (intracellular cAMP concentration); CF (cystic fibrosis); CFBE41o- (cystic fibrosis bronchial epithelium); CFTR (cystic fibrosis transmembrane conductance regulator); COPD (Chronic Obstructive Pulmonary Disease); IBMX (3-isobutyl-1-methylxanthine); PDE (phosphodiesterase); pHBE (primary human bronchial epithelium); PF (PF-04957325).

\section{Acknowledgements}

We thank the Biobank of respiratory tissues at the Centre Hospitalier de l'Universite de Montréal and Institut de recherche cliniques de Montréal, and Julie Goepp, Carolina Martini and Jessica de la Torre of the CF Canada Primary Airway Cell Biobank at McGill CFTRc for cell isolation and primary culture. We also thank Dr. Scott H. Randell at the University of North Carolina for providing pHBE F508del/R117H-5T cells. In addition, we extend our thanks to the Advanced Bioimaging Facility at McGill University for technical input for the FLIM-FRET studies. FACS was performed in the Flow Cytometry Core Facility of the Life Science Complex, McGill University and supported by funding from the Canadian Foundation for Innovation.

\section{Author Contributions}

M.J.T. conceived the study, designed experiments, acquired, analysed and interpretated data and drafted the manuscript. Y.S. acquired, analysed and interpreted data and drafted the manuscript. D.Y.T, K.A-B. and J.W.H. critically revised and edited the manuscript. 


\section{Cellular Physiology Cell Physiol Biochem 2021;55:784-804 \\ \begin{tabular}{ll|l}
\hline DOI: 10.33594/000000477 & ( 2021 The Author(s). Published by
\end{tabular} \\ Published online: 23 December 2021 Cell Physiol Biochem Press GmbH\&Co. KG \\ Turner et al.: Phosphodiesterase 8A Regulates CFTR Activity}

\section{Funding}

This work was funded by a fellowship awarded to M.J.T. from Verona Pharma plc with support from the UK CF Trust, and grants from Verona Pharma plc and the Canadian Institutes of Health Research to JWH and DYT.

\section{Statement of Ethics}

Human lung tissue was obtained under protocols approved by Institutional Review Boards at McGill University (\# A08-M70-14B) and the University of North Carolina at Chapel Hill.

\section{Disclosure Statement}

Partial support for this research was provided by Verona Pharma and KAB was an employee of Verona Pharma plc when the study was undertaken. Verona Pharma plc and Pfizer Inc. did not influence the design of the experiments or interpretation of the results.

\section{References}

1 Riordan JR: CFTR function and prospects for therapy. Annu Rev Biochem 2008;77:701-726.

2 Csanady L, Vergani P, Gadsby DC: Structure, gating, and regulation of the CFTR anion channel. Physiol Rev 2019;99:707-738.

3 Riordan JR, Rommens JM, Kerem B, Alon N, Rozmahel R, Grzelczak Z, Zielenski J, Lok S, Plavsic N, Chou JL, Drumm ML, Iannuzzi MC, Collins FS, Tsui LC: Identification of the cystic fibrosis gene: cloning and characterization of complementary DNA. Science 1989;245:1066-1073.

4 Rommens JM, Iannuzzi MC, Kerem B, Drumm ML, Melmer G, Dean M, Rozmahel R, Cole JL, Kennedy D, Hidaka N, Zsiga M, Buchwald M, Tsui LC, Riordan JR, Collins FS: Identification of the cystic fibrosis gene: chromosome walking and jumping. Science 1989;245:1059-1065.

5 Kerem B-S, Rommens JM, Buchanan JA, Markiewicz D, Cox TK, Chakravarti A, Buchwald M, Tsui LC: Identification of the cystic fibrosis gene: Genetic analysis. Science 1989;245:1073-1080.

6 Ratjen F, Bell SC, Rowe SM, Goss CH, Quittner AL, Bush A: Cystic fibrosis. Nature reviews Disease primers 2015;1:15010.

7 Dahan D, Evagelidis A, Hanrahan JW, Hinkson DA, Jia Y, Luo J, Zhu T: Regulation of the CFTR channel by phosphorylation. Pflugers Arch 2001;443:S92-96.

8 Maurice DH, Ke H, Ahmad F, Wang Y, Chung J, Manganiello VC: Advances in targeting cyclic nucleotide phosphodiesterases. Nature reviews Drug discovery 2014;13:290-314.

9 Conti M, Mika D, Richter W: Cyclic AMP compartments and signaling specificity: role of cyclic nucleotide phosphodiesterases. J Gen Physiol 2014;143:29-38.

10 Penmatsa H, Zhang W, Yarlagadda S, Li C, Conoley VG, Yue J, Bahouth SW, Buddington RK, Zhang G, Nelson DJ, Sonecha MD, Manganiello V, Wine JJ, Naren AP: Compartmentalized cyclic adenosine 3',5'-monophosphate at the plasma membrane clusters PDE3A and cystic fibrosis transmembrane conductance regulator into microdomains. Mol Biol Cell 2010;21:1097-1110.

11 Cobb BR, Fan L, Kovacs TE, Sorscher EJ, Clancy JP: Adenosine receptors and phosphodiesterase inhibitors stimulate Cl- secretion in Calu-3 cells. Am J Respir Cell Mol Biol 2003;29:410-418.

12 Kelley TJ, al-Nakkash L, Drumm ML: CFTR-mediated chloride permeability is regulated by type III phosphodiesterases in airway epithelial cells. Am J Respir Cell Mol Biol 1995;13:657-664.

13 Shen BQ Finkbeiner WE, Wine JJ, Mrsny RJ, Widdicombe JH: Calu-3: a human airway epithelial cell line that shows cAMP-dependent Cl- secretion. Am J Physiol 1994;266:L493-501.

14 Barnes AP, Livera G, Huang P, Sun C, O’Neal WK, Conti M, Stutts MJ, Milgram SL: Phosphodiesterase $4 \mathrm{D}$ forms a cAMP diffusion barrier at the apical membrane of the airway epithelium. J Biol Chem 2005;280:7997-8003. 


\section{Cellular Physiology Cell Physiol Biochem 2021;55:784-804 \begin{tabular}{l|l|l} 
and Binch $10.33594 / 000000477$ & 2021 The Author(s). Published by
\end{tabular} and BIOChemistry Published online: 23 December 2021 Cell Physiol Biochem Press GmbH\&Co. KG

15 Lambert JA, Raju SV, Tang LP, McNicholas CM, Li Y, Courville CA, Farris RF, Coricor GE, Smoot LH, Mazur MM, Dransfield MT, Bolger GB, Rowe SM: Cystic fibrosis transmembrane conductance regulator activation by roflumilast contributes to therapeutic benefit in chronic bronchitis. Am J Respir Cell Mol Biol 2014;50:549558.

16 Turner MJ, Matthes E, Billet A, Ferguson AJ, Thomas DY, Randell SH, Ostrowski LE, Abbott-Banner K, Hanrahan JW: The dual phosphodiesterase 3 and 4 inhibitor RPL554 stimulates CFTR and ciliary beating in primary cultures of bronchial epithelia. Am J Physiol Lung Cell Mol Physiol 2016;310:L59-70.

17 Blanchard E, Zlock L, Lao A, Mika D, Namkung W, Xie M, Scheitrum C, Gruenert DC, Verkman AS, Finkbeiner WE, Conti M, Richter W: Anchored PDE4 regulates chloride conductance in wild-type and DeltaF508-CFTR human airway epithelia. FASEB J 2014;28:791-801.

18 Schmid A, Baumlin N, Ivonnet P, Dennis JS, Campos M, Krick S, Salathe M: Roflumilast partially reverses smoke-induced mucociliary dysfunction. Respir Res 2015;16:135.

19 Tyrrell J, Qian X, Freire J, Tarran R: Roflumilast combined with adenosine increases mucosal hydration in human airway epithelial cultures after cigarette smoke exposure. Am J Physiol Lung Cell Mol Physiol 2015;308:L1068-1077.

20 Turner MJ, Luo Y, Thomas DY, Hanrahan JW: The dual phosphodiesterase 3/4 inhibitor RPL554 stimulates rare class III and IV CFTR mutants. Am J Physiol Lung Cell Mol Physiol 2020;318:L908-L920.

21 Robert R, Carlile GW, Pavel C, Liu N, Anjos SM, Liao J, Luo Y, Zhang D, Thomas DY, Hanrahan JW: Structural analog of sildenafil identified as a novel corrector of the F508del-CFTR trafficking defect. Mol Pharmacol 2008;73:478-489.

22 Lubamba B, Lebacq J, Reychler G, Marbaix E, Wallemacq P, Lebecque P, Leal T: Inhaled phosphodiesterase type 5 inhibitors restore chloride transport in cystic fibrosis mice. Eur Respir J 2011;37:72-78.

23 Rab A, Rowe SM, Raju SV, Bebok Z, Matalon S, Collawn JF: Cigarette smoke and CFTR: implications in the pathogenesis of COPD. Am J Physiol Lung Cell Mol Physiol 2013;305:L530-541.

24 Turner MJ, Abbott-Banner K, Thomas DY, Hanrahan JW: Cyclic nucleotide phosphodiesterase inhibitors as therapeutic interventions for cystic fibrosis. Pharmacol Ther 2021;224:107826.

25 Fisher DA, Smith JF, Pillar JS, St Denis SH, Cheng JB: Isolation and characterization of PDE8A, a novel human cAMP-specific phosphodiesterase. Biochem Biophys Res Commun 1998;246:570-577.

26 Vang AG, Ben-Sasson SZ, Dong H, Kream B, DeNinno MP, Claffey MM, Housley W, Clark RB, Epstein PM, Brocke S: PDE8 regulates rapid Teff cell adhesion and proliferation independent of ICER. PLoS One 2010;5:e12011.

27 Basole CP, Nguyen RK, Lamothe K, Vang A, Clark R, Baillie GS, Epstein PM, Brocke S: PDE8 controls CD4(+) T cell motility through the PDE8A-Raf-1 kinase signaling complex. Cell Signal 2017;40:62-72.

28 Patrucco E, Albergine MS, Santana LF, Beavo JA: Phosphodiesterase 8A (PDE8A) regulates excitationcontraction coupling in ventricular myocytes. J Mol Cell Cardiol 2010;49:330-333.

29 Dong H, Claffey KP, Brocke S, Epstein PM: Inhibition of breast cancer cell migration by activation of cAMP signaling. Breast Cancer Res Treat 2015;152:17-28.

30 Lounas A, Vernoux N, Germain M, Tremblay ME, Richard FJ: Mitochondrial sub-cellular localization of cAMP-specific phosphodiesterase 8A in ovarian follicular cells. Sci Rep 2019;9:12493.

31 Shimizu-Albergine M, Tsai LC, Patrucco E, Beavo JA: cAMP-specific phosphodiesterases 8A and 8B, essential regulators of Leydig cell steroidogenesis. Mol Pharmacol 2012;81:556-566.

32 Vasta V, Shimizu-Albergine M, Beavo JA: Modulation of Leydig cell function by cyclic nucleotide phosphodiesterase 8A. Proc Natl Acad Sci U S A 2006;103:19925-19930.

33 Johnstone TB, Smith KH, Koziol-White CJ, Li F, Kazarian AG, Corpuz ML, Shumyatcher M, Ehlert FJ, Himes BE, Panettieri RA, Jr., Ostrom RS: PDE8 Is Expressed in Human Airway Smooth Muscle and Selectively Regulates cAMP Signaling by beta2-Adrenergic Receptors and Adenylyl Cyclase 6. Am J Respir Cell Mol Biol 2018;58:530-541.

34 Bebok Z, Collawn JF, Wakefield J, Parker W, Li Y, Varga K, Sorscher EJ, Clancy JP: Failure of cAMP agonists to activate rescued deltaF508 CFTR in CFBE41o- airway epithelial monolayers. J Physiol 2005;569:601-615.

35 Fulcher ML, Gabriel S, Burns KA, Yankaskas JR, Randell SH: Well-differentiated human airway epithelial cell cultures. Methods Mol Med 2005;107:183-206.

36 Klarenbeek J, Goedhart J, van Batenburg A, Groenewald D, Jalink K: Fourth-generation epac-based FRET sensors for cAMP feature exceptional brightness, photostability and dynamic range: characterization of dedicated sensors for FLIM, for ratiometry and with high affinity. PLoS One 2015;10:e0122513. 


\section{Cellular Physiology Cell Physiol Biochem 2021;55:784-804 \begin{tabular}{ll|l} 
DOI: 10.33594/000000477 & (c)21 The Author(s). Published by
\end{tabular} and BiOChemistry Published online: 23 December 2021 Cell Physiol Biochem Press GmbH\&Co. KG \\ Turner et al.: Phosphodiesterase 8A Regulates CFTR Activity}

37 Goedhart J, von Stetten D, Noirclerc-Savoye M, Lelimousin M, Joosen L, Hink MA, van Weeren L, Gadella TW, Jr., Royant A: Structure-guided evolution of cyan fluorescent proteins towards a quantum yield of $93 \%$. Nat Commun 2012;3:751.

38 Chen L, Ye HL, Zhang G, Yao WM, Chen XZ, Zhang FC, Liang G: Autophagy inhibition contributes to the synergistic interaction between EGCG and doxorubicin to kill the hepatoma Hep3B cells. PLoS One 2014;9:e85771.

39 Fuhrmann M, Jahn HU, Seybold J, Neurohr C, Barnes PJ, Hippenstiel S, Kraemer HJ, Suttorp N: Identification and function of cyclic nucleotide phosphodiesterase isoenzymes in airway epithelial cells. Am J Respir Cell Mol Biol 1999;20:292-302.

40 Smith SJ, Brookes-Fazakerley S, Donnelly LE, Barnes PJ, Barnette MS, Giembycz MA: Ubiquitous expression of phosphodiesterase 7A in human proinflammatory and immune cells. Am J Physiol Lung Cell Mol Physiol 2003;284:L279-289.

41 Wright LC, Seybold J, Robichaud A, Adcock IM, Barnes PJ: Phosphodiesterase expression in human epithelial cells. Am J Physiol 1998;275:L694-700.

42 Cowley EA, Linsdell P: Characterization of basolateral K+ channels underlying anion secretion in the human airway cell line Calu-3. J Physiol 2002;538:747-757.

43 Preston P, Wartosch L, Gunzel D, Fromm M, Kongsuphol P, Ousingsawat J, Kunzelmann K, Barhanin J, Warth R, Jentsch TJ: Disruption of the K+ channel beta-subunit KCNE3 reveals an important role in intestinal and tracheal Cl- transport. J Biol Chem 2010;285:7165-7175.

44 Li C, Krishnamurthy PC, Penmatsa H, Marrs KL, Wang XQ, Zaccolo M, Jalink K, Li M, Nelson DJ, Schuetz JD, Naren AP: Spatiotemporal coupling of cAMP transporter to CFTR chloride channel function in the gut epithelia. Cell 2007;131:940-951.

45 Cheung L, Flemming CL, Watt F, Masada N, Yu DM, Huynh T, Conseil G, Tivnan A, Polinsky A, Gudkov AV, Munoz MA, Vishvanath A, Cooper DM, Henderson MJ, Cole SP, Fletcher JI, Haber M, Norris MD: Highthroughput screening identifies Ceefourin 1 and Ceefourin 2 as highly selective inhibitors of multidrug resistance protein 4 (MRP4). Biochem Pharmacol 2014;91:97-108.

46 Keating D, Marigowda G, Burr L, Daines C, Mall MA, McKone EF, Ramsey BW, Rowe SM, Sass LA, Tullis E, McKee CM, Moskowitz SM, Robertson S, Savage J, Simard C, Van Goor F, Waltz D, Xuan F, Young T, TaylorCousar JL, et al.: VX-445-Tezacaftor-Ivacaftor in Patients with Cystic Fibrosis and One or Two Phe508del Alleles. N Engl J Med 2018;379:1612-1620.

47 Middleton PG, Mall MA, Drevinek P, Lands LC, McKone EF, Polineni D, Ramsey BW, Taylor-Cousar JL, Tullis E, Vermeulen F, Marigowda G, McKee CM, Moskowitz SM, Nair N, Savage J, Simard C, Tian S, Waltz D, Xuan F, Rowe SM, et al.: Elexacaftor-Tezacaftor-Ivacaftor for Cystic Fibrosis with a Single Phe508del Allele. N Engl J Med 2019;381:1809-1819.

48 Matthes E, Goepp J, Martini C, Shan J, Liao J, Thomas DY, Hanrahan JW: Variable Responses to CFTR Correctors in vitro: Estimating the Design Effect in Precision Medicine. Front Pharmacol 2018;9:1490.

49 Soderling SH, Bayuga SJ, Beavo JA: Cloning and characterization of a cAMP-specific cyclic nucleotide phosphodiesterase. Proc Natl Acad Sci U S A 1998;95:8991-8996.

50 Brown KM, Day JP, Huston E, Zimmermann B, Hampel K, Christian F, Romano D, Terhzaz S, Lee LC, Willis MJ, Morton DB, Beavo JA, Shimizu-Albergine M, Davies SA, Kolch W, Houslay MD, Baillie GS: Phosphodiesterase8A binds to and regulates Raf-1 kinase. Proc Natl Acad Sci U S A 2013;110:E1533-1542.

51 Koschinski A, Zaccolo M: Activation of PKA in cell requires higher concentration of cAMP than in vitro: implications for compartmentalization of cAMP signalling. Sci Rep 2017;7:14090.

52 Huang P, Lazarowski ER, Tarran R, Milgram SL, Boucher RC, Stutts MJ: Compartmentalized autocrine signaling to cystic fibrosis transmembrane conductance regulator at the apical membrane of airway epithelial cells. Proc Natl Acad Sci U S A 2001;98:14120-14125.

53 Leier G, Bangel-Ruland N, Sobczak K, Knieper Y, Weber WM: Sildenafil acts as potentiator and corrector of CFTR but might be not suitable for the treatment of CF lung disease. Cell Physiol Biochem 2012;29:775790.

54 MacKenzie SJ, Baillie GS, McPhee I, MacKenzie C, Seamons R, McSorley T, Millen J, Beard MB, van Heeke G, Houslay MD: Long PDE4 cAMP specific phosphodiesterases are activated by protein kinase A-mediated phosphorylation of a single serine residue in Upstream Conserved Region 1 (UCR1). Br J Pharmacol 2002;136:421-433. 


\section{Cellular Physiology Cell Physiol Biochem 2021;55:784-804 \begin{tabular}{ll|l|l|l} 
DOI: 10.33594/000000477 & (0)21 The Author(s). Published by
\end{tabular} and Biochemistry Published online: 23 December 2021 Cell Physiol Biochem Press GmbH\&Co. KG \\ Turner et al.: Phosphodiesterase 8A Regulates CFTR Activity}

55 Demirbas D, Wyman AR, Shimizu-Albergine M, Cakici O, Beavo JA, Hoffman CS: A yeast-based chemical screen identifies a PDE inhibitor that elevates steroidogenesis in mouse Leydig cells via PDE8 and PDE4 inhibition. PLoS One 2013;8:e71279.

56 Golkowski M, Shimizu-Albergine M, Suh HW, Beavo JA, Ong SE: Studying mechanisms of cAMP and cyclic nucleotide phosphodiesterase signaling in Leydig cell function with phosphoproteomics. Cell Signal 2016;28:764-778.

57 Monterisi S, Casavola V, Zaccolo M: Local modulation of cystic fibrosis conductance regulator: cytoskeleton and compartmentalized cAMP signalling. Br J Pharmacol 2013;169:1-9.

58 Montoro DT, Haber AL, Biton M, Vinarsky V, Lin B, Birket SE, Yuan F, Chen S, Leung HM, Villoria J, Rogel N, Burgin G, Tsankov AM, Waghray A, Slyper M, Waldman J, Nguyen L, Dionne D, Rozenblatt-Rosen O, Tata PR, et al.: A revised airway epithelial hierarchy includes CFTR-expressing ionocytes. Nature 2018;560:319-324.

59 Okuda K, Dang H, Kobayashi Y, Carraro G, Nakano S, Chen G, Kato T, Asakura T, Gilmore RC, Morton LC, Lee RE, Mascenik T, Yin WN, Barbosa Cardenas SM, O’Neal YK, Minnick CE, Chua M, Quinney NL, Gentzsch M, Anderson CW, et al.: Secretory Cells Dominate Airway CFTR Expression and Function in Human Airway Superficial Epithelia. Am J Respir Crit Care Med 2021;203:1275-1289.

60 Plasschaert LW, Zilionis R, Choo-Wing R, Savova V, Knehr J, Roma G, Klein AM, Jaffe AB: A single-cell atlas of the airway epithelium reveals the CFTR-rich pulmonary ionocyte. Nature 2018;560:377-381.

61 van Aubel RA, Smeets PH, Peters JG, Bindels RJ, Russel FG: The MRP4/ABCC4 gene encodes a novel apical organic anion transporter in human kidney proximal tubules: putative efflux pump for urinary cAMP and cGMP. J Am Soc Nephrol 2002;13:595-603.

62 Naren AP, Cobb B, Li C, Roy K, Nelson D, Heda GD, Liao J, Kirk KL, Sorscher EJ, Hanrahan J, Clancy JP: A macromolecular complex of beta 2 adrenergic receptor, CFTR, and ezrin/radixin/moesin-binding phosphoprotein 50 is regulated by PKA. Proc Natl Acad Sci U S A 2003;100:342-346.

63 Chen ZS, Lee K, Kruh GD: Transport of cyclic nucleotides and estradiol 17-beta-D-glucuronide by multidrug resistance protein 4. Resistance to 6-mercaptopurine and 6-thioguanine. J Biol Chem 2001;276:3374733754.

64 Copsel S, Garcia C, Diez F, Vermeulem M, Baldi A, Bianciotti LG, Russel FG, Shayo C, Davio C: Multidrug resistance protein 4 (MRP4/ABCC4) regulates cAMP cellular levels and controls human leukemia cell proliferation and differentiation. J Biol Chem 2011;286:6979-6988.

65 Lee RJ, Foskett JK: cAMP-activated Ca2 + signaling is required for CFTR-mediated serous cell fluid secretion in porcine and human airways. J Clin Invest 2010;120:3137-3148.

66 Klein H, Abu-Arish A, Trinh NT, Luo Y, Wiseman PW, Hanrahan JW, Brochiero E, Sauve R: Investigating CFTR and KCa3.1 Protein/Protein Interactions. PLoS One 2016;11:e0153665.

67 Vigone G, Shuhaibar LC, Egbert JR, Uliasz TF, Movsesian MA, Jaffe LA: Multiple cAMP Phosphodiesterases Act Together to Prevent Premature Oocyte Meiosis and Ovulation. Endocrinology 2018;159:2142-2152.

68 Turner MJ, Dauletbaev N, Lands LC, Hanrahan JW: The Phosphodiesterase Inhibitor Ensifentrine Reduces Production of Proinflammatory Mediators in Well Differentiated Bronchial Epithelial Cells by Inhibiting PDE4. J Pharmacol Exp Ther 2020;375:414-429.

69 Cantin AM, Hanrahan JW, Bilodeau G, Ellis L, Dupuis A, Liao J, Zielenski J, Durie P: Cystic fibrosis transmembrane conductance regulator function is suppressed in cigarette smokers. Am J Respir Crit Care Med 2006;173:1139-1144.

70 Raju SV, Rasmussen L, Sloane PA, Tang LP, Libby EF, Rowe SM: Roflumilast reverses CFTR-mediated ion transport dysfunction in cigarette smoke-exposed mice. Respir Res 2017;18:173. 